\title{
Behavior Evaluation of Ultrahigh-Performance Concrete Beam Containing Para-Aramid Fibers
}

\author{
Seung-Ki Kim, ${ }^{1}$ Woosuk Kim $\mathbb{D}^{1},{ }^{1}$ and Sang-Mook Han ${ }^{2}$ \\ ${ }^{1}$ School of Architecture, Kumoh National Institute of Technology, Republic of Korea \\ ${ }^{2}$ Department of Civil Engineering, Kumoh National Institute of Technology, Republic of Korea \\ Correspondence should be addressed to Woosuk Kim; kimw@kumoh.ac.kr
}

Received 12 November 2018; Accepted 14 April 2019; Published 20 May 2019

Academic Editor: Fabrizio Paolacci

Copyright (C) 2019 Seung-Ki Kim et al. This is an open access article distributed under the Creative Commons Attribution License, which permits unrestricted use, distribution, and reproduction in any medium, provided the original work is properly cited.

This experimental research was performed to evaluate the shear and flexural behavior for two cases of reinforced concrete beams: ultrahigh-performance concrete (UHPC) and normal-strength concrete jacketed with UHPC. The experiment was performed to examine the optimum para-aramid fiber to reinforce the ductile UHPC, with the test variables fiber diameter and length. Beam tests were then performed to evaluate the performance of the UHPC and jacketed beams. The UHPC beam tests with and without stirrups were conducted to evaluate flexural and shear behavior, respectively. The beam tests with and without jacketing were conducted to evaluate the reinforcement performance of UHPC.

\section{Introduction}

The importance of concrete has grown within the construction industry as a superior building material. Today, the strength of concrete, which affects the size and Manhattanization of buildings, can reach over $150 \mathrm{MPa}$; this type of concrete is called ultrahigh-performance concrete (UHPC). UHPC exhibits equal internal force with less thickness compared with normal-strength concrete (NSC) because of its high strength, so UHPC is judged more effective than NSC as a reinforcement material. Recently, more buildings and bridges are being constructed with UHPC; this trend is leading to research on, and utilization of, reinforcement for structures that are old or have insufficient seismic capacity $[1,2]$.

Concrete, which is known as a brittle material, overcomes its brittle property through fiber mixing [3-10]. The most superior fiber among the various fibers used in research is steel fiber. So far, because steel fiber is most effective, it is used in both NSC and UHPC. To replace steel fiber, studies have applied various fibers and have found fibers that have superior performance, such as carbon fiber and para-aramid (p-A) fiber [11-13].

In particular, $\mathrm{p}$-A fiber is a highly attractive material for improving the performance of concrete; it is considered an effective material for improving the performance of both NSC and UHPC. However, although studies applying p-A fiber to concrete are increasing, it is still in an insufficient state. Thus, an additional study is required to understand the reinforcement performance of $\mathrm{p}-\mathrm{A}$ fiber. The present study aimed to (1) test the material properties of UHPC with p-A fiber; (2) evaluate the flexural and shear behavior of UHPC beams; and (3) evaluate the flexural and shear behavior of NSC beams jacketed with UHPC.

\section{Experimental Program}

We have evaluated the compressive and bending strengths of UHPC in accordance with the mechanical properties of $\mathrm{p}-\mathrm{A}$ fiber before the UHPC beam test. The mix proportions used in this study was $150 \mathrm{MPa}$ UHPC. However, if $\mathrm{p}$-A fiber is used to reinforce the bending strength of UHPC, a decrease in compressive strength is expected [14, 15]. The mix proportions used in the experiments are shown in Table 1.

There were two main experiments in this study. The first was material testing to evaluate the compressive and bending strengths of the specimens. The second was structure testing to evaluate the shear and flexural behavior of NSC and UHPC beams. The experimental contents are detailed in Table 2. 
TABle 1: Mix proportions.

\begin{tabular}{|c|c|c|c|c|c|c|}
\hline Water & Binder & White sand & River sand & Sf & SP & Fiber \\
\hline \multicolumn{7}{|c|}{ Compression test } \\
\hline $0.24^{1}$ & 1.23 & 0.65 & 0.65 & 0.2 & 0.05 & Steel fiber \\
\hline \multicolumn{7}{|c|}{ Bending test } \\
\hline 0.24 & 1.23 & 0.65 & 0.65 & - & 0.04 & p-A fiber \\
\hline
\end{tabular}

Binder: cement, silica fume, and zirconium; Sf: silica flour; SP: superplasticizer.

TABle 2: Experimental contents.

\begin{tabular}{lccc}
\hline & Experiment & Parameters \\
\hline Fresh concrete & Slump flow & Compressive strength & - \\
& Materials test & Bending strength & Admixture \\
Hardened concrete & UHPC beam & Rebar ratio, fiber ratio, shear span-depth ratio \\
& Structure test & Jacketed beam & Jacketed thickness \\
\hline
\end{tabular}

2.1. Materials. In this study, we used small-particle materials because of their impact on concrete strength. The cement used was ordinary Portland cement (OPC). The binder elements (silica fume, zirconium, and silica flour) had a smaller particle size than is typically used $[16,17]$. We used zirconium to make an economical mix because in previous research, it was found that it improves flowability instead of reducing strength when used to replace silica fume [18, 19]. The material properties are detailed in Tables 3-8.

Many types of $\mathrm{p}$-A fiber were used in this study. The three parameters of $\mathrm{p}$-A fiber considered were diameter, length, and twisted or not. The types of $\mathrm{p}-\mathrm{A}$ fiber are detailed in Table 9. All types had equal properties other than these three parameters.

2.2. Materials Test. The purpose of the materials test was to investigate the influence of binder and the best geometrical properties of $\mathrm{p}-\mathrm{A}$ fiber when used to improve the strength of concrete. The test of compressive strength was performed with a $100 \times 200 \mathrm{~mm}$ concrete cylinder. Parameters other than binder combination were fixed to evaluate only the influence of the binder in the cylinder test, and binder combination is shown in Table 10. The test of bending strength in accordance with p-A fiber type was performed with a $100 \times 100 \times 400 \mathrm{~mm}$ beam mold. Three specimens of cylinders and beam were made with each combination of parameters. Experiments were performed to conform to two KS standards, KS F 2405 (Standard Test Method for Compressive Strength of Concrete) and KS F 2566 (Standard Test Method for Flexural Performance of FiberReinforced Concrete). The test setup is shown in Figures 1 and 2 . In the bending test, because $\mathrm{p}$-A fiber has more influence on the decrease in flowability than steel fiber $[14,20]$, we fixed the p-A fiber ratio and controlled only the amount of SP to satisfy sufficient flowability on the basis of mix proportion.

2.3. Shear and Flexural Behavior Test of UHPC Beams. This section describes the test method for the UHPC beams. Two aspects were tested: flexural behavior and shear behavior. The two types of specimens had one common parameter, fiber ratio; the other parameters were tension reinforcement ratio and shear span-depth ratio. The tension reinforcement ratio was selected by reference to Korean code $\mathrm{KCI}-2012$ 6.3.2. In the Korean code, the minimum reinforcement ratio is regulated as

$$
\begin{aligned}
\rho_{\text {min }} & =\frac{0.25 \sqrt{f_{\mathrm{ck}}}}{f_{\mathrm{y}}}, \\
\text { or } \rho_{\text {min }} & =\frac{1.4}{f_{\mathrm{y}}},
\end{aligned}
$$

where $f_{\mathrm{ck}}$ is the specified concrete compressive strength and $f_{\mathrm{y}}$ is the specified steel yield stress. It is the same data used in standard ACI 318-14. In the ACI code, the reason for regulating the minimum reinforcement ratio shown is as follows: "With a small amount of tension reinforcement required for strength, the calculated moment strength of a reinforced concrete section using cracked section analysis becomes less than that of the corresponding unreinforced concrete section calculated from its modulus of rupture. Failure in such a case could occur at first cracking and without warning. To prevent such a failure, a minimum amount of tension reinforcement is required in both positive and negative moment regions."

The reinforcement ratio was determined based on the minimum reinforcement ratio to evaluate whether equation (1) was applicable to UHPC. The shear span-depth ratio was determined to three values based on Lee's work [21]. The fiber ratio satisfying the most superior strength and flowability was used for the materials test.

A total of 12 specimens were fabricated and tested under the displacement control method until failure. Each specimen's properties are shown in Table 11. Those section and rebar placing are shown in Figure 3. The test setup was a four-point bending configuration, as shown in Figure 4 $[22,23]$. We attached one steel strain gauge at the bottom of each reinforcement steel, so a total of two steel strain gauges were used, as shown in Figure 5. Three concrete strain gauges were then attached in a vertical orientation at 
TABle 3: Physical properties of cement.

\begin{tabular}{lcccccc}
\hline \multirow{2}{*}{ Density $\left(\mathrm{g} / \mathrm{cm}^{3}\right)$} & Fineness $\left(\mathrm{cm}^{2} / \mathrm{g}\right)$ & \multicolumn{2}{c}{ Setting time $(\mathrm{min})$} & \multicolumn{3}{c}{ Compressive strength $(\mathrm{MPa})$} \\
& & Initial & Final & 3 days & 7 days & 28 days \\
\hline 3.15 & 3,200 & 230 & 390 & 22 & 29 & 40 \\
\hline
\end{tabular}

TABle 4: Chemical composition and physical properties of silica fume.

\begin{tabular}{lccccccc}
\hline \multirow{2}{*}{ Density $\left(\mathrm{g} / \mathrm{cm}^{3}\right)$} & \multirow{2}{*}{ Retention $45 \mu \mathrm{m}(\%)$} & L.O.I (\%) & \multicolumn{3}{c}{ Chemical composition (\%) } \\
& & & $\mathrm{SiO}_{2}$ & $\mathrm{Fe}_{2} \mathrm{O}_{3}$ & $\mathrm{Al}_{2} \mathrm{O}_{3}$ & $\mathrm{CaO}$ & $\mathrm{MgO}^{2}$ \\
\hline 2.2 & 1.0 & 1.04 & 96.32 & 0.41 & 0.08 & 0.09 & 0.55 \\
\hline
\end{tabular}

TABLE 5: Chemical composition and physical properties of zirconium.

\begin{tabular}{lcccccrr}
\hline \multirow{2}{*}{ Density $\left(\mathrm{g} / \mathrm{cm}^{3}\right)$} & Retention $45 \mu \mathrm{m}(\%)$ & L.O.I (\%) & \multicolumn{3}{c}{ Chemical composition (\%) } \\
& & & $\mathrm{SiO}_{2}$ & $\mathrm{Fe}_{2} \mathrm{O}_{3}$ & $\mathrm{Al}_{2} \mathrm{O}_{3}$ & $\mathrm{CaO}$ & $\mathrm{MgO}^{2}$ \\
\hline 2.2 & 0.2 & 1.01 & 94.3 & 0.1 & 0.2 & 0.01 \\
\hline
\end{tabular}

TABLE 6: Physical properties of aggregates.

\begin{tabular}{lcccc}
\hline Classification & Density $\left(\mathrm{g} / \mathrm{cm}^{3}\right)$ & Fineness modulus & Unit weight $\left(\mathrm{kg} / \mathrm{m}^{3}\right)$ & Absorption ratio $(\%)$ \\
\hline White sand & 2.6 & 1.23 & 1,610 & 0.1 \\
River sand & 2.6 & 0.45 & 1,520 & 0.1 \\
\hline
\end{tabular}

TABLE 7: Physical properties of filler.

\begin{tabular}{lcccccc}
\hline & \multirow{2}{*}{ Density $\left(\mathrm{g} / \mathrm{cm}^{3}\right)$} & Retention $45 \mu \mathrm{m}(\%)$ & \multicolumn{3}{c}{ Chemical composition (\%) } \\
& & & $\mathrm{SiO}_{2}$ & $\mathrm{Fe}_{2} \mathrm{O}_{3}$ & $\mathrm{Al}_{2} \mathrm{O}_{3}$ & $\mathrm{CaO}$ \\
\hline Silica flour & 2.61 & $0(12.4 \mu \mathrm{m})$ & 99.8 & 0.07 & 0.06 & 0.02 \\
LCD glass & 2.61 & 94.3 & - & - & - & - \\
\hline
\end{tabular}

TABLE 8: Chemical properties of superplasticizer.

\begin{tabular}{lccc}
\hline Ingredient & Type & Density $\left(\mathrm{g} / \mathrm{cm}^{3}\right)$ & $\mathrm{pH}$ \\
\hline Polycarbonate & Fluid & 1.05 & $6 \pm 1$ \\
\hline
\end{tabular}

TABle 9: Physical properties of p-A fibers.

\begin{tabular}{|c|c|c|c|c|c|}
\hline Fiber number & Density $\left(\mathrm{g} / \mathrm{cm}^{3}\right)$ & Diameter $(\mathrm{mm})$ & Length (mm) & Twisted & Tensile strength $(\mathrm{MPa})$ \\
\hline p-A $4-13$ & \multirow{14}{*}{1.44} & \multirow{4}{*}{0.2} & 13 & 0 & \multirow{4}{*}{2600} \\
\hline p-A 4-19 & & & 19 & 0 & \\
\hline p-A $4-13 \mathrm{~T}$ & & & 13 & \multirow{3}{*}{150} & \\
\hline p-A $4-19 T$ & & & 19 & & \\
\hline p-A $10-13$ & & \multirow{6}{*}{0.32} & 13 & & \multirow{6}{*}{1950} \\
\hline p-A $10-19$ & & & 19 & \multirow[t]{3}{*}{0} & \\
\hline p-A $10-25$ & & & 25 & & \\
\hline p-A $10-13 T$ & & & 13 & & \\
\hline p-A $10-19 T$ & & & 19 & 100 & \\
\hline $\mathrm{p}-\mathrm{A} 10-25 \mathrm{~T}$ & & & 25 & & \\
\hline p-A $15-13 T$ & & \multirow{4}{*}{0.38} & 13 & \multirow{4}{*}{-} & \multirow{4}{*}{-} \\
\hline p-A $15-19 \mathrm{~T}$ & & & 19 & & \\
\hline p-A $15-25 \mathrm{~T}$ & & & 25 & & \\
\hline p-A $15-30 T$ & & & 30 & & \\
\hline
\end{tabular}

p-A 4-13T: p-A: para-aramid; $4:$ denier $(4 \longrightarrow 400 \mathrm{D}, 10 \longrightarrow 1000 \mathrm{D}, 15 \longrightarrow 1500 \mathrm{D})$; 13: length $(13,19,25,30)$; T: twist. 
TABLE 10: Binder combinations for compression testing.

\begin{tabular}{lcccc}
\hline Number & 1 & 2 & 3 & 4 \\
\hline Binder combination & Cement, silica fume & Cement, silica fume, zirconium & Cement, zirconium & Cement, silica fume (posoco) \\
\hline
\end{tabular}

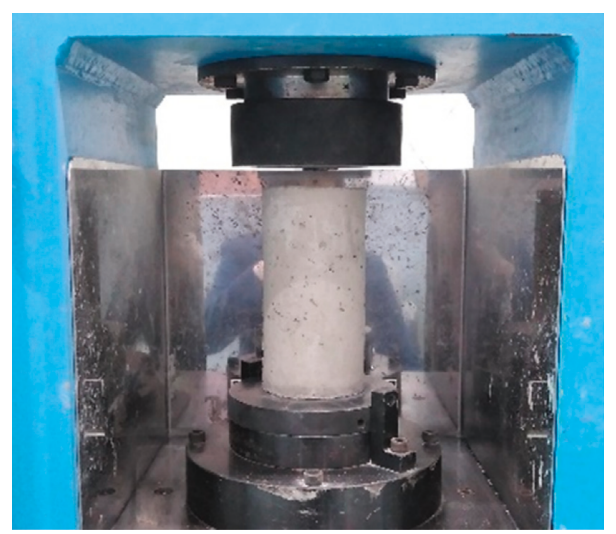

Figure 1: Compression test setup.

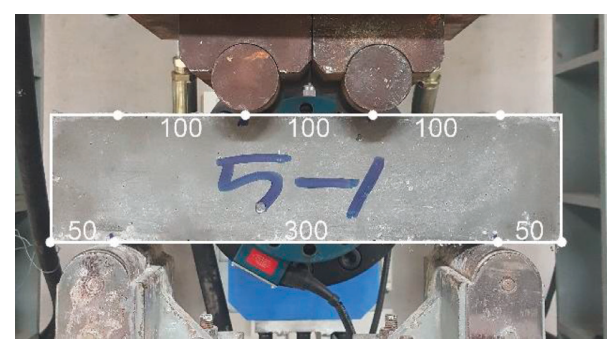

Figure 2: Bending test setup.

TABLE 11: The list of UHPC beam specimens.

\begin{tabular}{|c|c|c|c|c|c|c|c|}
\hline & \multirow{2}{*}{ Set number } & \multirow{2}{*}{ Section $(\mathrm{mm})$} & \multirow{2}{*}{ Fiber ratio (vol.\%) } & \multicolumn{2}{|c|}{ Reinforcement steel } & \multirow{2}{*}{ Shear span-depth ratio } & \multirow{2}{*}{ Length $(\mathrm{mm})$} \\
\hline & & & & Ratio (\%) & Place & & \\
\hline $\begin{array}{l}\text { HS2-N } \\
\text { HS2-A }\end{array}$ & 1 & \multirow{10}{*}{$135 \times 270$} & 0 & \multirow{5}{*}{1.1} & \multirow{5}{*}{ 2-D16 } & 2 & 1,630 \\
\hline HS3-N & \multirow[b]{2}{*}{2} & & $\begin{array}{l}1 \\
0\end{array}$ & & & \multirow{4}{*}{3} & \multirow{2}{*}{2,100} \\
\hline HS3-A & & & 1 & & & & \\
\hline HS4-N & \multirow{2}{*}{3} & & 0 & & & & \multirow{7}{*}{2,560} \\
\hline HS4-A & & & 1 & & & & \\
\hline HB4-N & \multirow{2}{*}{4} & & 0 & 04 & & \multirow{5}{*}{4} & \\
\hline HB4-A & & & 1 & \multirow{2}{*}{0.7} & $2-010$ & & \\
\hline HB7-N & 5 & & 0 & & 2-D13 & & \\
\hline $\begin{array}{l}\text { HB7-A } \\
\text { HB11-N }\end{array}$ & \multirow{2}{*}{6} & & $\begin{array}{l}1 \\
0\end{array}$ & \multirow{2}{*}{1.1} & \multirow{2}{*}{ 2-D16 } & & \\
\hline HB11-A & & & 1 & & & & \\
\hline
\end{tabular}

the center line. The shear behavior test specimens also had one additional concrete strain gauge at the center of each line connecting the loading point and support point [24-26].

2.4. Shear and Flexural Behavior Test of NSC Beams Jacketed with UHPC. This section describes the test method for the NSC beams jacketed with UHPC. Two aspects were tested: flexural behavior and shear behavior. The purpose of the test was to evaluate the performance of UHPC when used as a jacketing method. The test setup was the same as that of the UHPC beam test with regard to loading state and strain gauge location. The area and thickness reinforced by UHPC was selected in accordance with reinforcing performance. Shear specimens were reinforced at the front and back [1]. Flexural specimens were further reinforced at the bottom in the shear-jacketed area [27]. The test setup was the same as that of the UHPC beams. The specimen contents are detailed in Table 12. 

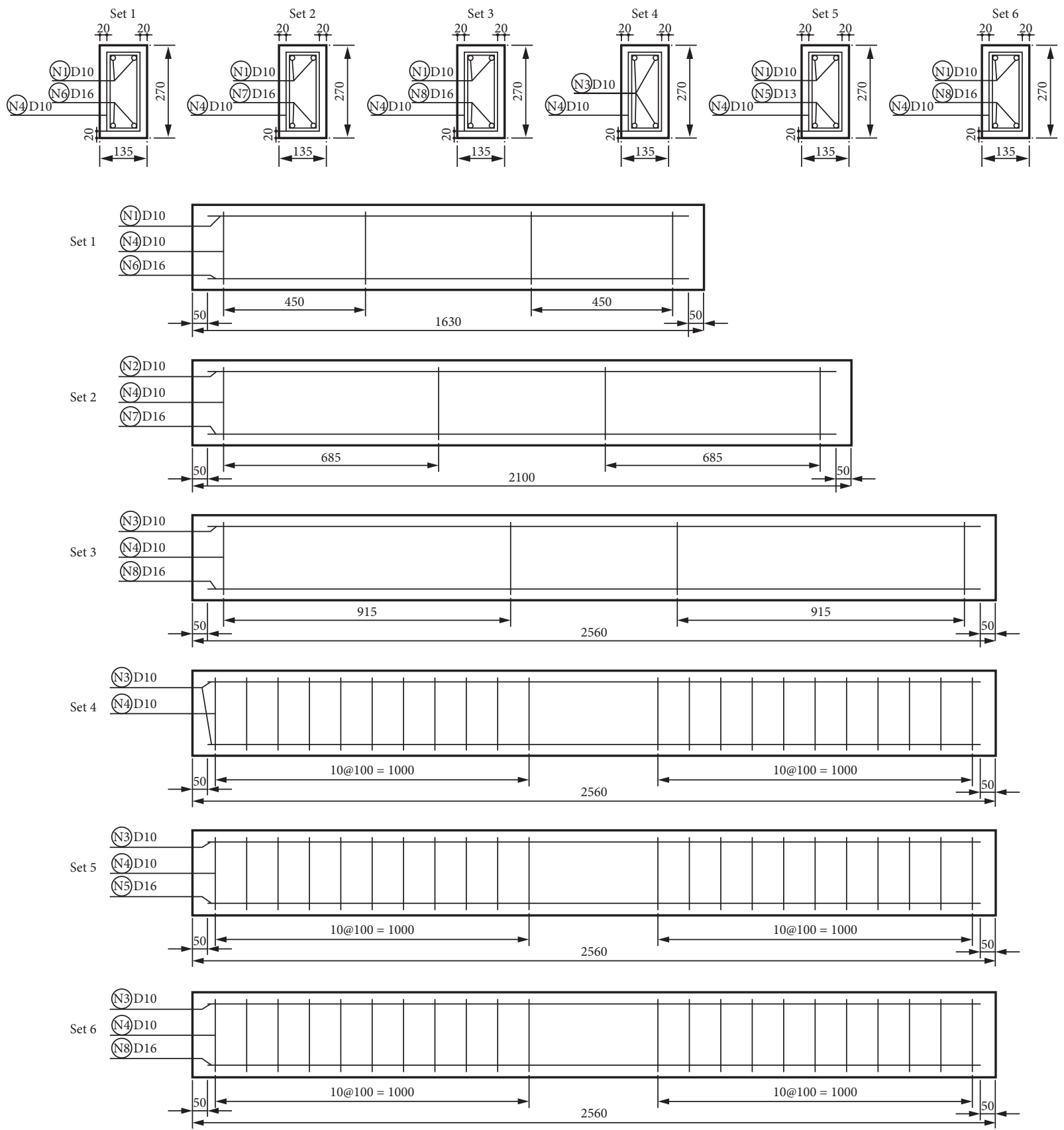

FIGURE 3: UHPC beam specimens spacing list.

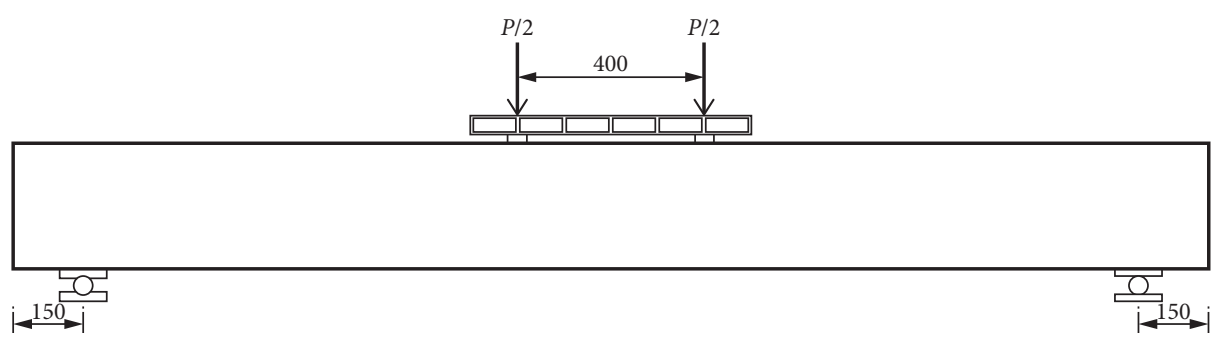

FIGURE 4: Setup of the UHPC beam test.

A total of six specimens were made and tested under displacement control until failure. Those section and jacketed areas are shown in Figures 6 and 7. The test setup was a four-point bending configuration. The location and method of attaching strain gauges were the same as those described for the UHPC beam test. 


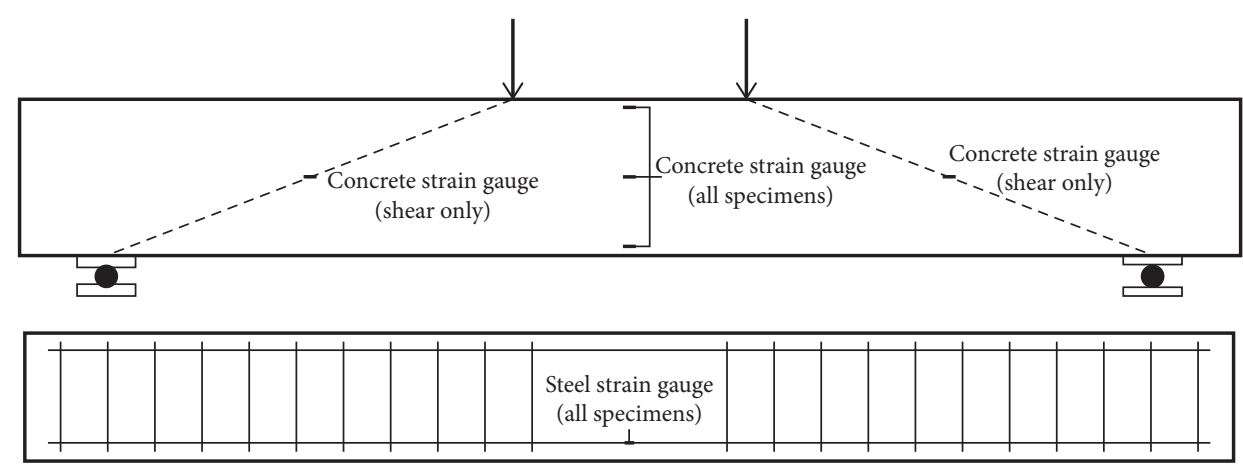

FIGURE 5: Strain gauge locations.

TABLE 12: The list of NSC beam jacketed UHPC specimens.

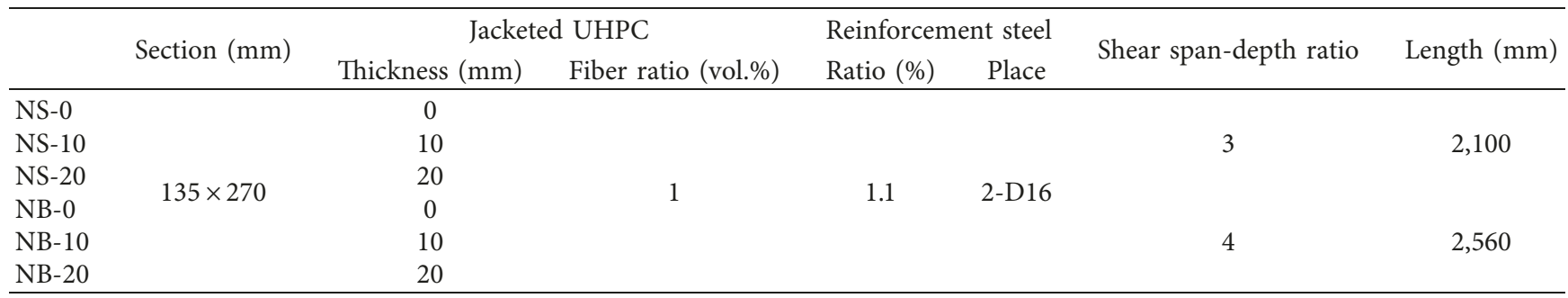

\section{Test Results}

3.1. Materials Test Results. The compressive strength test results are shown in Table 13 and Figure 8. In the test results, compressive strength was related to silica fume. The specimens with silica fume exhibited higher strength than those with zirconium, but slump flow was decreased. Therefore, an increment in the addition of superplasticizer is needed. We should prudently determine the mix proportion in view of the economic aspects because binders and superplasticizer are closely related.

The bending strength test results are shown in Table 14 and Figure 9. A graph of bending strength according to fiber diameter is shown in Figure 10. The effect of $\mathrm{p}$-A fiber varied depending on the diameter, length, and twist of the fiber. For fibers with the same length and diameter, the twisted p-A fiber exhibited a higher flexural strength than the nontwisted fiber. When $0.2 \mathrm{~mm}$ diameter fibers were used, specimens of $13 \mathrm{~mm}$ length with twist have the highest strength, but the effect of length decreased with twisted fibers. When $0.32 \mathrm{~mm}$ diameter fibers were used, the p-A fiber with the highest reinforcing performance was $19 \mathrm{~mm}$ length with no twist and $25 \mathrm{~mm}$ length with twist. All specimens of $0.38 \mathrm{~mm}$ diameter had twisting; among them, the $13 \mathrm{~mm}$ fiber had the highest strength.

For the $0.2 \mathrm{~mm}$ diameter fiber specimens, brittle failure was observed at maximum load with or without twisting. It is considered that the reinforcement effect was excellent because the surface area was larger than that of other specimens because of the small diameter. Increasing surface area leads to a decrease in flowability, which means an increase in the superplasticizer requirement. Although twisting was used to improve the surface area, it was effective in their specimens. For the $0.32 \mathrm{~mm}$ diameter fiber specimens, ductile failure was observed with twisting and brittle failure was observed with no twisting. It balanced the reinforcing effect and adhesive force. Ductile failure exhibited after the maximum load. For the $0.38 \mathrm{~mm}$ diameter fiber specimens, brittle failure was observed under every condition.

In this study, the optimum fiber sizes were p-A 4-13T and $-19 \mathrm{~T}$. However, the results considered only strength according to fiber size. Thus, we must consider not only reinforcing strength but also economy. The smallerdiameter fiber is more expensive. Thus, we exclude the $0.2 \mathrm{~mm}$ diameter fiber considering economy and chose the $0.32 \mathrm{~mm}$ diameter fiber instead. The $\mathrm{p}-\mathrm{A} 10-19 \mathrm{~T}$ and $-25 \mathrm{~T}$ were the most effective among the $0.32 \mathrm{~mm}$ diameter fibers. We chose the p-A 10-19T because the fiber length influences the flowability and ductile performance.

Twist, diameter, and length of fiber are closely connected with flexural behavior. When the fiber used to improve flexural strength was short, the fiber diameter was short; the more effective the reinforcement was, the most effective the twist was. However, fiber length was not linearly related with fiber diameter. Therefore, many more studies are required to exactly evaluate the influence of various sizes of $\mathrm{p}-\mathrm{A}$ fiber to finally derive the optimum fiber. Further studies are then needed to evaluate reinforcing performance.

3.2. UHPC Beam Test Results. The shear test results are shown in Figures 11 and 12 and Table 15. The specimens were placed in stirrups for only the minimum amount required to induce shear failure. Shear or diagonal tension failure was exhibited in specimens without fiber, and flexural failure was exhibited in fiber-reinforced specimens. The strength of all fiber-reinforced specimens was increased. In 


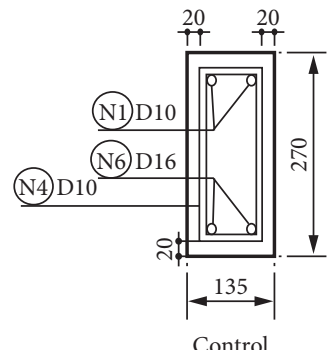

Control

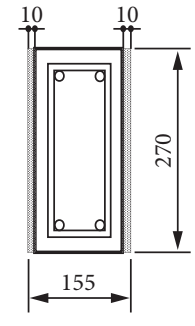

Thickness $10 \mathrm{~mm}$ Shear specimens

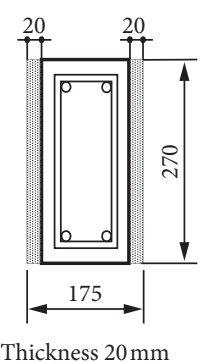

Thickness $20 \mathrm{~mm}$

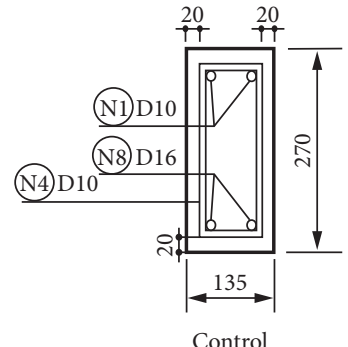

Control

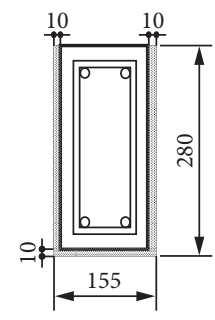

Thickness $10 \mathrm{~mm}$ Flexural specimens

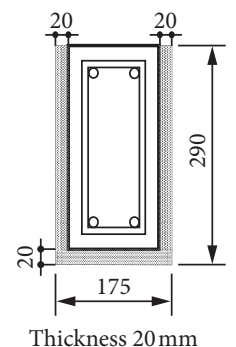

Thickness $20 \mathrm{~mm}$

FIgURE 6: Section of NSC beams jacketed with UHPC.
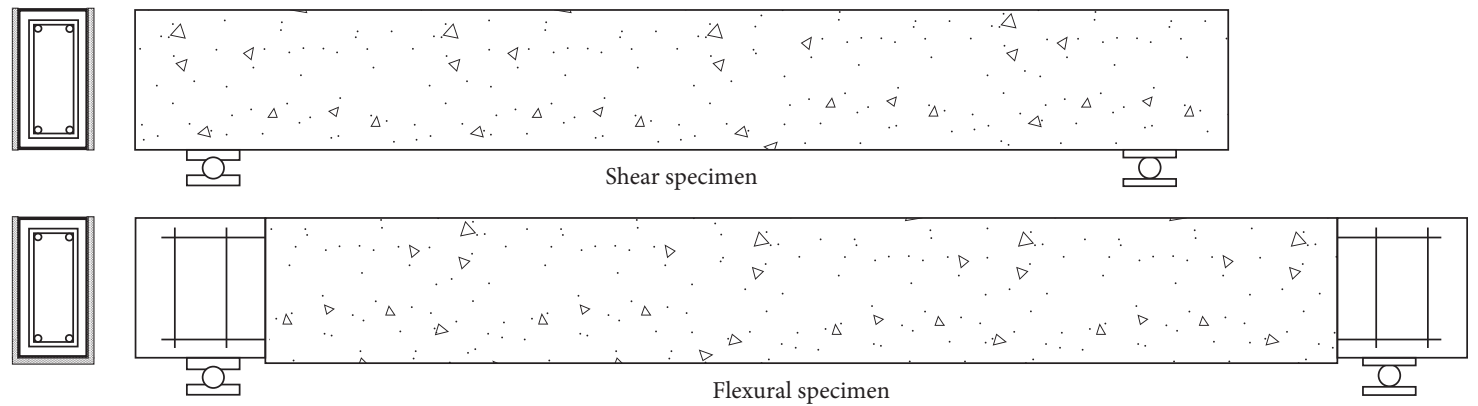

Figure 7: Side elevation of NSC beams jacketed with UHPC.

TABle 13: Compression test results.

\begin{tabular}{lcccc}
\hline & 1 & 2 & 3 & 4 \\
\hline Compressive strength $(\mathrm{MPa})$ & 137.8 & 129.9 & 113.7 & 110.2 \\
Strain & 0.0026 & 0.0033 & 0.0031 & 0.0036 \\
\hline
\end{tabular}

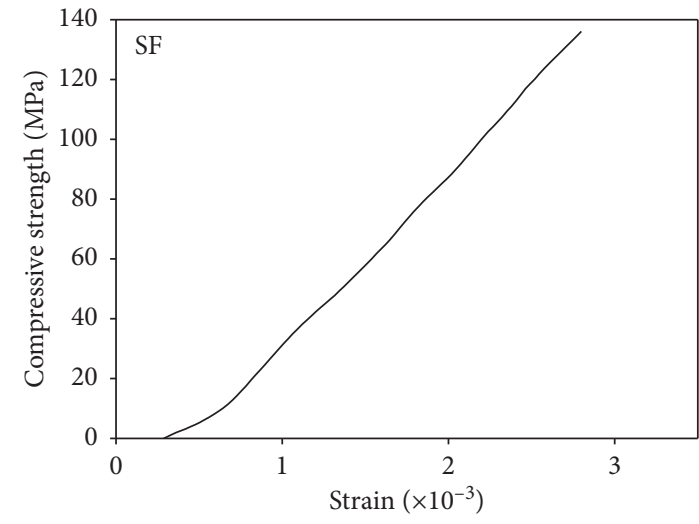

(a)

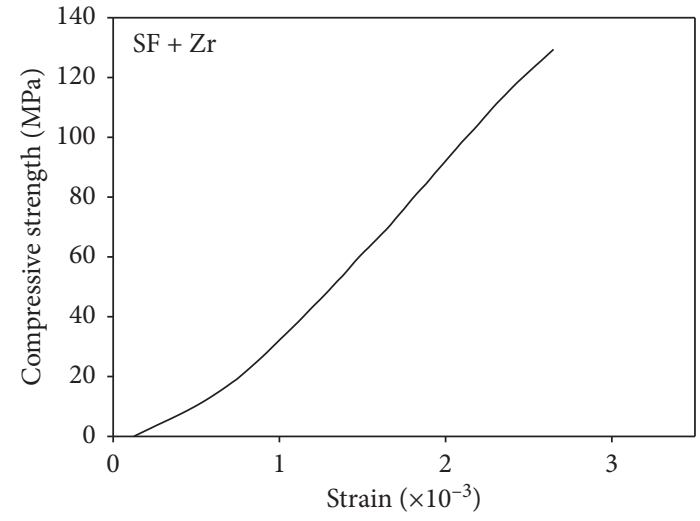

(b)

FIgURe 8: Continued. 


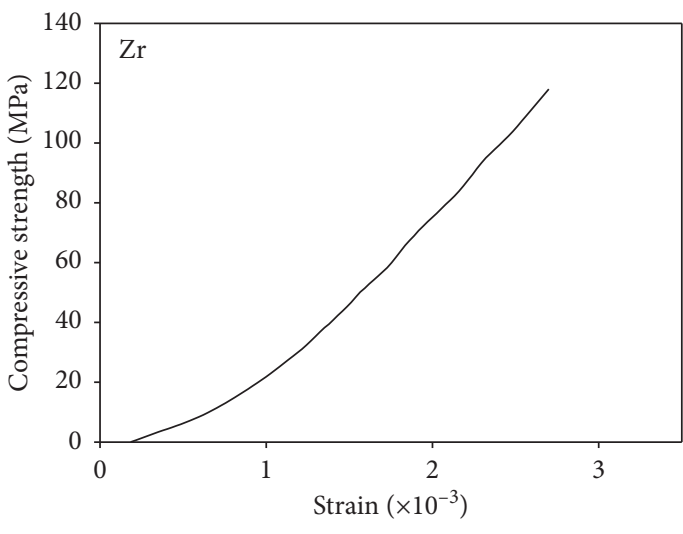

(c)

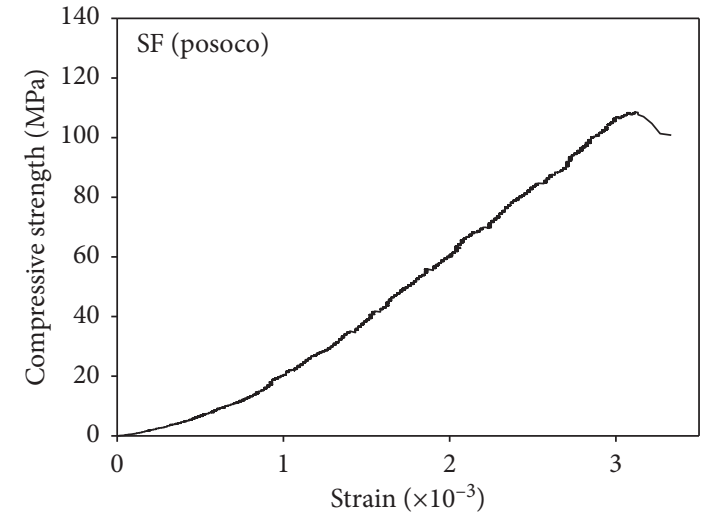

(d)

Figure 8: Compression strength-strain graphs. (a) Silica fume. (b) Silica fume and zirconium. (c) Zirconium. (d) Silica fume (posoco).

TABLE 14: Bending test results.

\begin{tabular}{|c|c|c|}
\hline & Bending strength $(\mathrm{MPa})$ & Displacement $(\mathrm{mm})$ \\
\hline p-A 4-13 & 13.6 & 4.48 \\
\hline p-A 4-19 & 13.2 & 4.20 \\
\hline p-A $4-13 \mathrm{~T}$ & 14.9 & 4.47 \\
\hline p-A $4-19 T$ & 14.8 & 4.73 \\
\hline p-A $10-13$ & 10.6 & 4.96 \\
\hline p-A $10-19$ & 12.1 & 4.60 \\
\hline p-A $10-25$ & 11.8 & 4.13 \\
\hline p-A $10-13 T$ & 12.7 & 4.68 \\
\hline p-A $10-19 \mathrm{~T}$ & 13.2 & 4.12 \\
\hline p-A $10-25 \mathrm{~T}$ & 13.6 & 4.41 \\
\hline p-A $15-13 T$ & 11.8 & 5.28 \\
\hline p-A $15-19 T$ & 9.3 & 5.64 \\
\hline p-A $15-25 \mathrm{~T}$ & 10.1 & 5.57 \\
\hline p-A $15-30 \mathrm{~T}$ & 10.0 & 6.67 \\
\hline
\end{tabular}

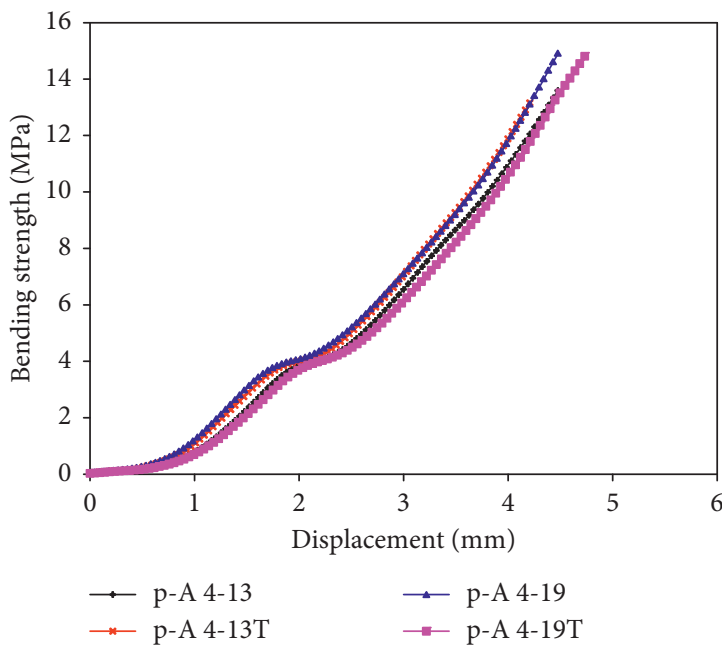

(a)

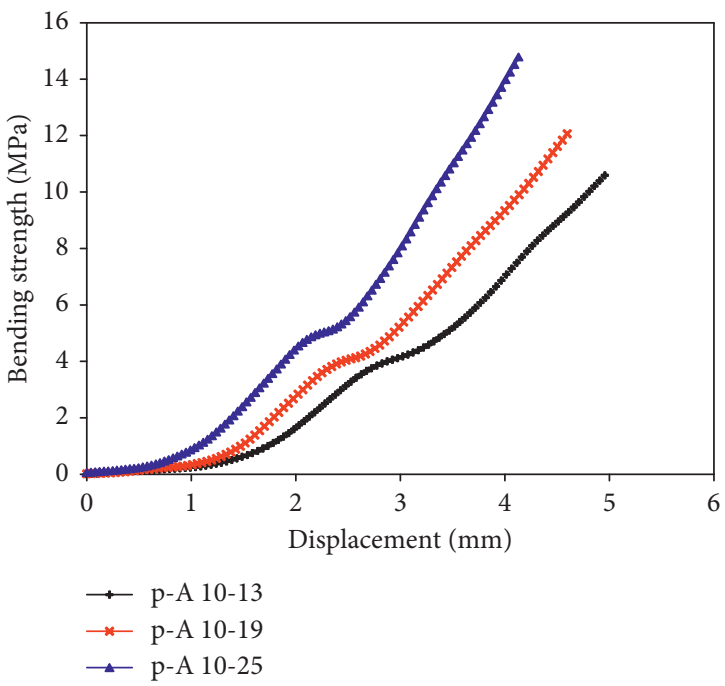

(b)

Figure 9: Continued. 

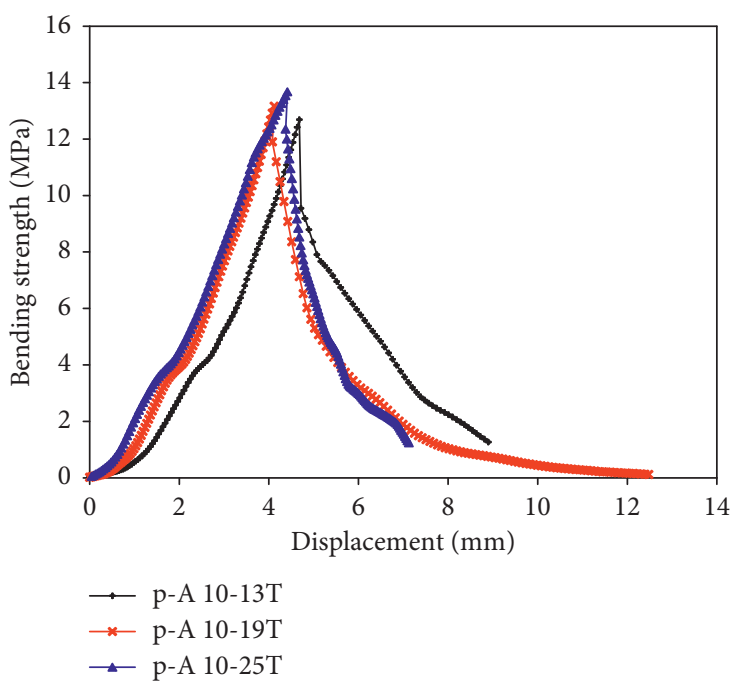

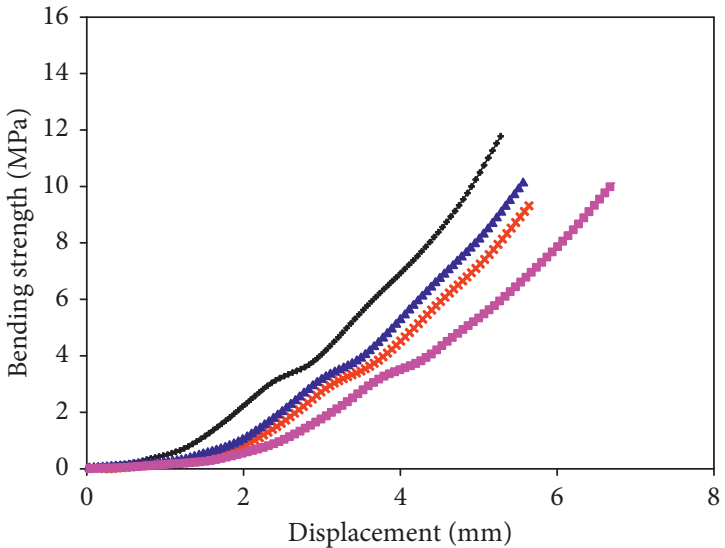

$\rightarrow$ p-A 15-13T $\rightarrow$ p-A 15-25T
$*$ p-A 15-19T $\rightarrow$ p-A 15-30T

(d)

(c)

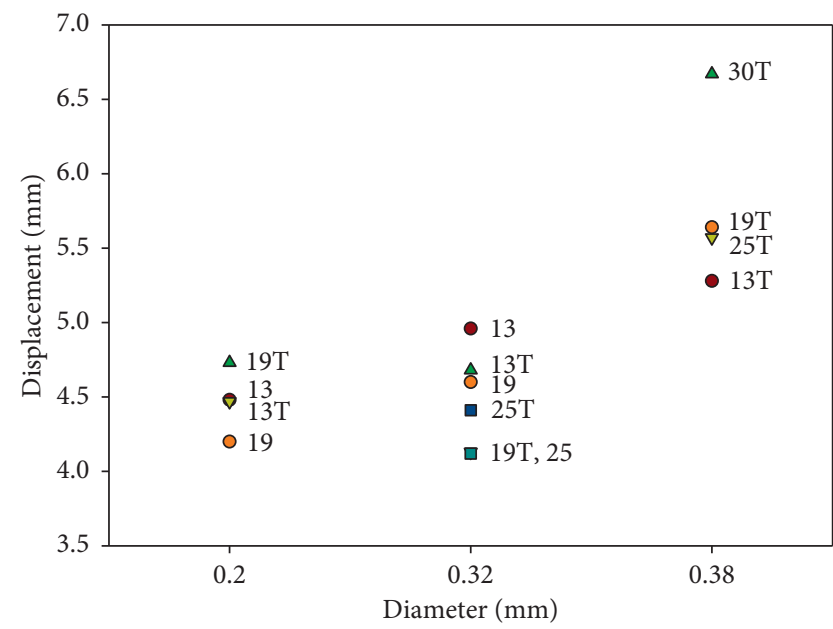

(b)

FIgURE 10: Bending strength and displacement according to fiber diameter.

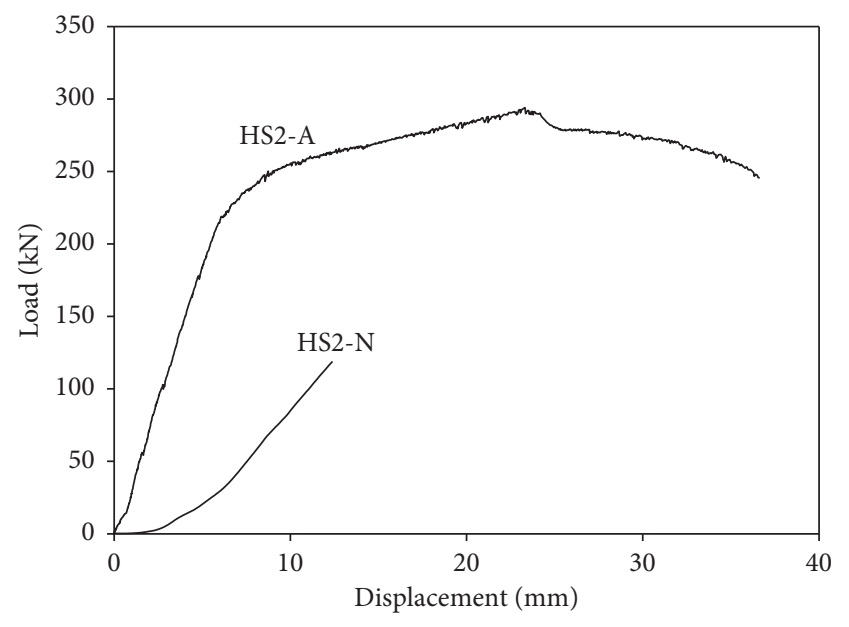

(a)

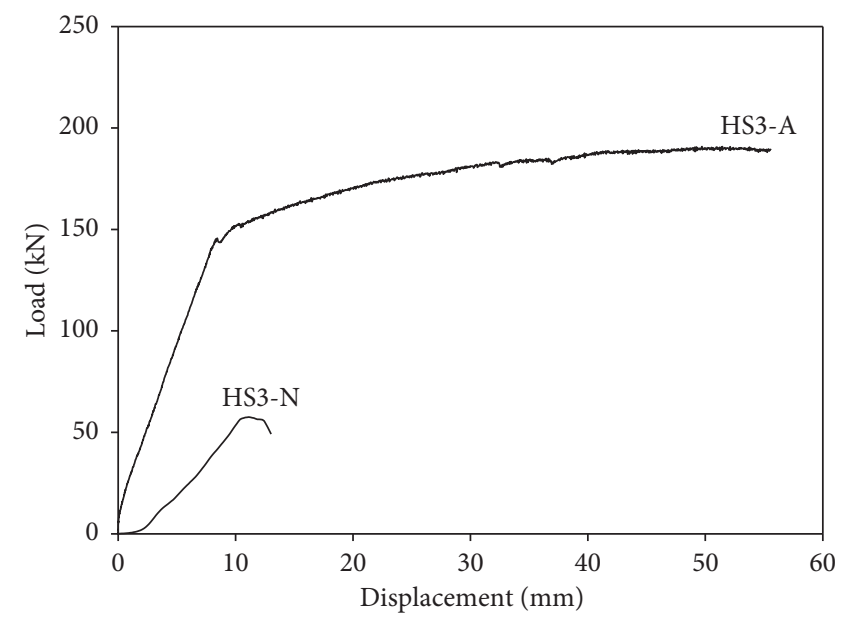

(b)

Figure 11: Continued. 


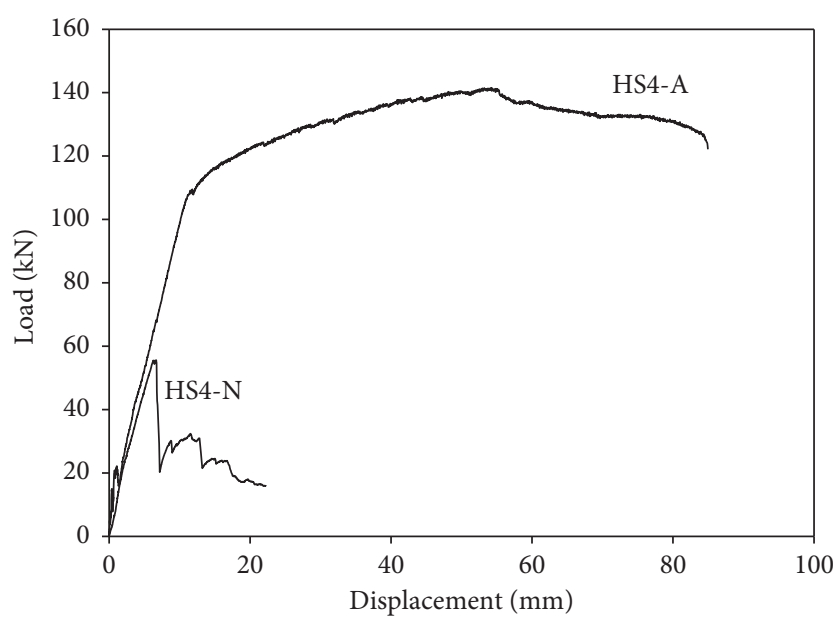

(c)

FIGURE 11: Load-displacement curve of UHPC shear specimens.

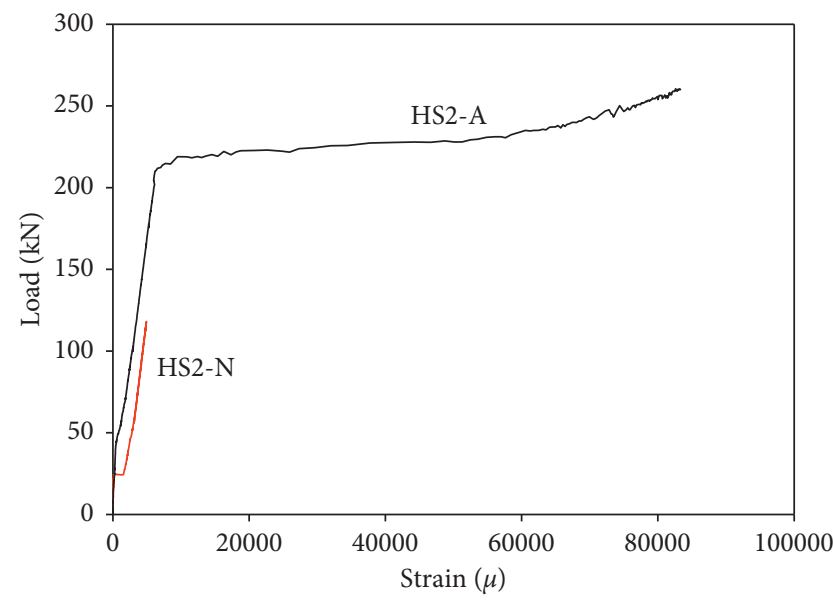

(a)

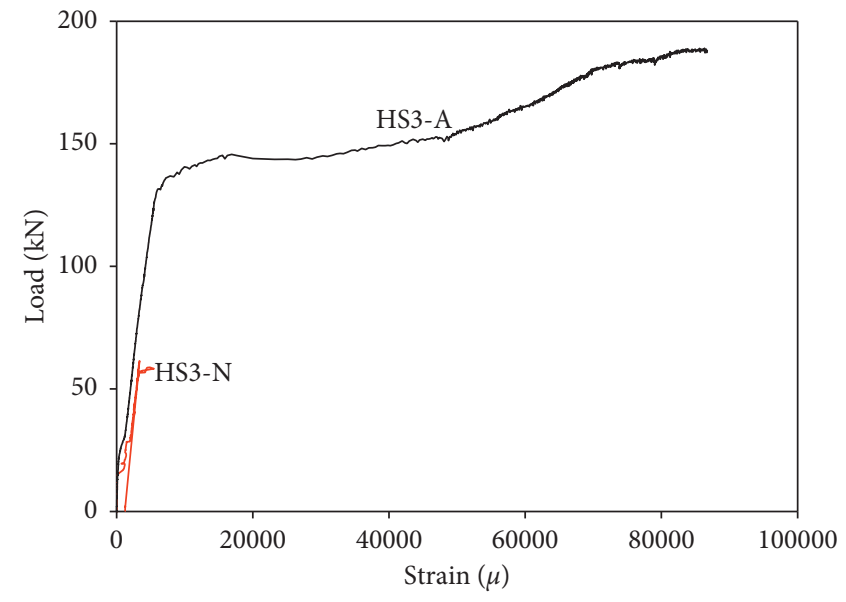

(b)

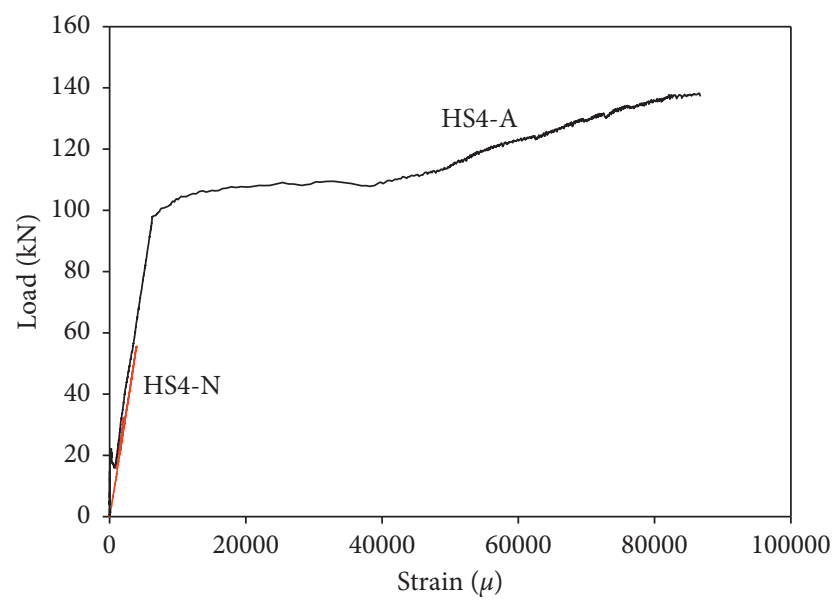

(c)

FIGURE 12: Load-steel strain curve of UHPC shear specimens.

specimens with a shear span-depth ratio of 2 , the initial crack load was increased by $130 \%$, diagonal tension crack load was $155 \%$, and ultimate load was $150 \%$. For a shear span-depth ratio of 3 , the initial crack load was increased by $236 \%$ and the ultimate load was increased by $210 \%$, and diagonal tension cracking did not occur. For a shear span-depth ratio 
TABle 15: Shear load of UHPC shear specimens.

\begin{tabular}{lccccc}
\hline & Initial crack load, $V_{\mathrm{i}}(\mathrm{kN})$ & Diagonal tension crack load, $V_{\mathrm{cr}}(\mathrm{kN})$ & Ultimate shear load, $V_{\mathrm{u}}(\mathrm{kN})$ & $V_{\mathrm{i}} / V_{\mathrm{u}}$ & $V_{\mathrm{cr}} / V_{\mathrm{u}}$ \\
\hline HS2-N & 23.0 & 76.28 & 118.04 & 0.19 & 0.65 \\
HS2-A & 53.0 & 195.2 & $294.01(\mathrm{~F})$ & 0.18 & 0.66 \\
HS3-N & 9.9 & 43.55 & 61.46 & 0.16 & 0.71 \\
HS3-A & 33.3 & - & $190.86(\mathrm{~F})$ & 0.17 & - \\
HS4-N & 6.0 & 28.0 & 55.63 & 0.11 & 0.50 \\
HS4-A & 20.0 & - & $141.57(\mathrm{~F})$ & 0.14 & - \\
\hline
\end{tabular}

F: flexural failure specimens, therefore indicating ultimate flexural load.

of 4 , the initial crack load was increased by $230 \%$ and ultimate load was increased by $150 \%$, and diagonal tension cracking did not occur. The ratio of the initial crack load and ultimate load was similar with or without p-A fiber. We can deduce that the $\mathrm{p}$-A fiber was effective for reinforcing the shear strength of concrete beams through the test results that showed a change in the failure mode from shear to flexural.

Figure 13 displays the crack patterns of UHPC shear specimens. The specimens without $\mathrm{p}$-A fibers indicated typical shear failure which destroyed simultaneously with diagonal tension crack. These results were the same for all specimens without shear depth-width ratio. In HS2-A and HS3-A, the cracks were divided into smaller cracks and the number of cracks increased due to the presence of p-A fiber. The diagonal tension crack occurred, but this did not lead to shear failure and eventually resulted in flexural failure yielding of the bottom rebar. In the case of HS4-A, the crack trend indicated similar result to HS2-A and HS3-A. However, the diagonal tension crack did not occur and typical flexural failure was indicated. Through these results, we identified that the p-A fiber had the effect of crack control in high-strength concrete. We expected that the crack control of the p-A fiber was related to the effect of shear reinforcement. In terms of flexural strength, the experimental ultimate flexural load of specimens with p-A fiber was indicated approximately 1.3 1.4 times than the calculated ultimate flexural load. The shear load was increased over $150 \%$ after mixing the p-A fiber, but this was a minimum value. We did not establish the ultimate shear load because these specimens experienced flexural failure.

The flexure test results are shown in Figures 14 and 15 and Table 16. Flexural strength was increased after fiber inclusion, regardless of the tension reinforcement ratio. The initial crack load increased with increasing tension reinforcement ratio and the mixing of fiber. The initial crack load increased more when the tension reinforcement ratio increased. From these results, we surmised that there was a proportional interaction between the tension reinforcement ratio and $\mathrm{p}$-A fiber ratio.

The strength and displacement at the yield point increased after fiber inclusion, but the strength and displacement at the ultimate state were similar with or without fiber. The ductility index was rather decreased after mixing in the fiber. The ductility index of the HB4 specimen was decreased from 14.74 to 6.34 , representing the largest change. The ductility index of the HB7 and HB11 specimens decreased 20\%. The strength increase exhibited before the yield point; however, after yielding the tension reinforcement steel, the p-A fiber did not demonstrate sufficient performance.

Figure 16 displays the crack patterns of UHPC flexural specimens. HB4-N and HB11-N indicated the compressive failure between loading points, which changed to flexural failure mode and did not indicate the compressive failure after p-A fiber mixing. Furthermore, the effect of crack control was identified.

3.3. Jacketed Beam Test Results. This section discusses the results of testing NSC beams jacketed with UHPC. The shear specimen data are as shown in Figure 17 and Table 17. The strength of the $10 \mathrm{~mm}$ jacketed specimen was similar to that of the plain specimen. However, the strength of the NS-20 specimens increased by $20 \%$ compared with specimens NS-0 and NS-10. The bottom steel of NS-0 and NS-10 did not yield, but NS- 20 yielded, which means that NS- 0 and NS- 10 exhibited shear failure and NS-20 exhibited flexural failure. These results showed that using UHPC was appropriate for reinforcing NSC beams. However, NS-20 showed a trend of continuously decreasing load in the ductility region after the yield point. This was due to insufficient adhesion, so reinforced-section delamination occurred. If the UHPC jacketing fails to satisfy the adhesion requirement, the beam strength increases before the yield point but decreases in the ductility region.

Figure 18 displays the crack patterns of NSC shear specimens. NS-0 indicated the typical shear failure as diagonal shear failure. The cracks mostly occurred at the outside of the loading point. In the crack pattern of NS-10, after delamination of the reinforcement section, the cracks were not transferred from the NSC beam to the reinforcement section. Because of this, the behavior of the jacketed beam could not be identified from the crack pattern.

The NS-20 indicated the failure occurred in the flexural failure mode between the loading points. It did not lose adhesion until the ultimate load, and we identified the shear reinforcement effect.

Retaining a balance between adhesion and UHPC, thickness must be satisfied to exhibit sufficient reinforcement performance prior to shear. The location of the jacketed area in this study was only to the side of the beam. Consequently, each UHPC jacketed beam side can be considered as separate structures during the experiment.

The flexural specimen's behavior data are shown in Figure 19 and Table 18. The strength of the $10 \mathrm{~mm}$ reinforced 


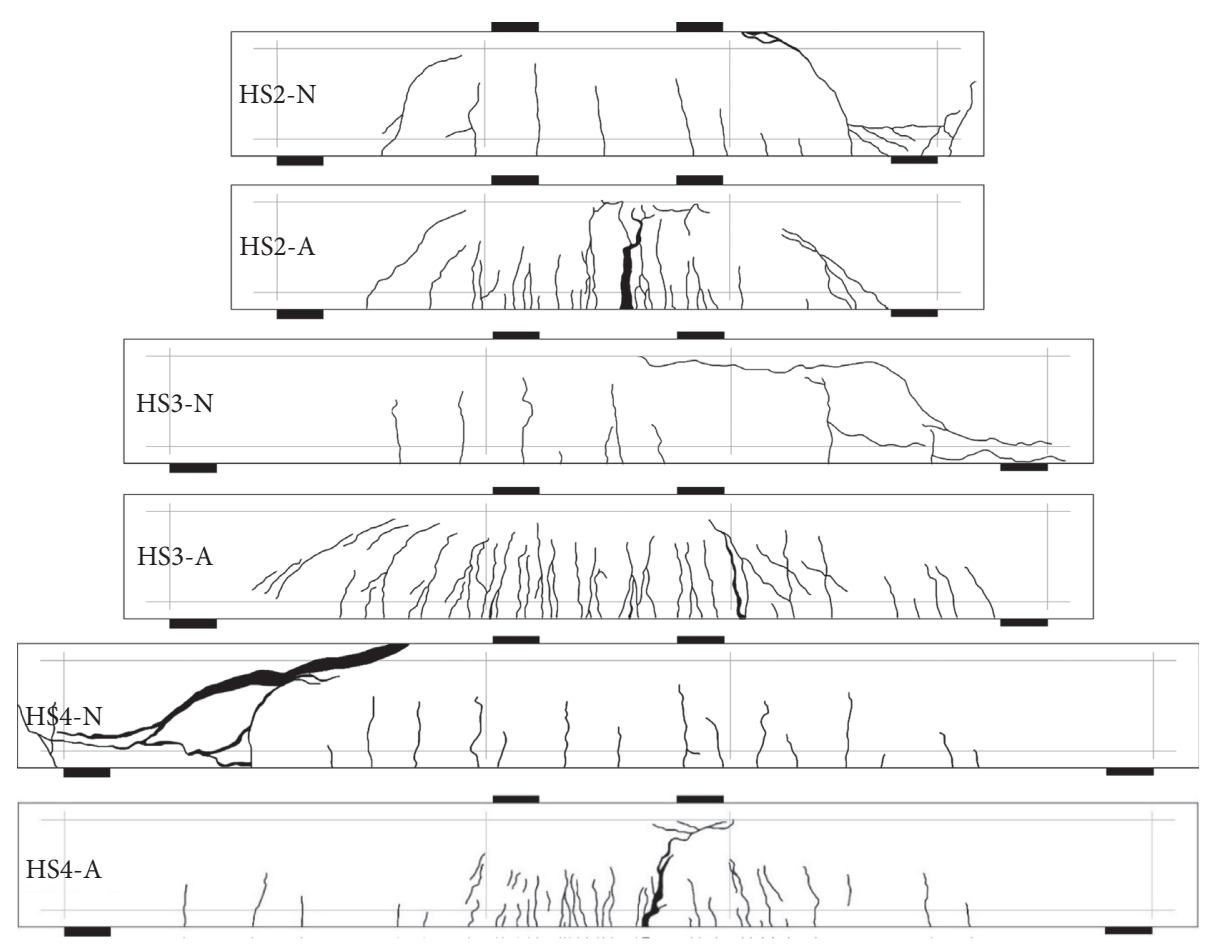

FIGURE 13: Crack patterns of UHPC shear specimens.

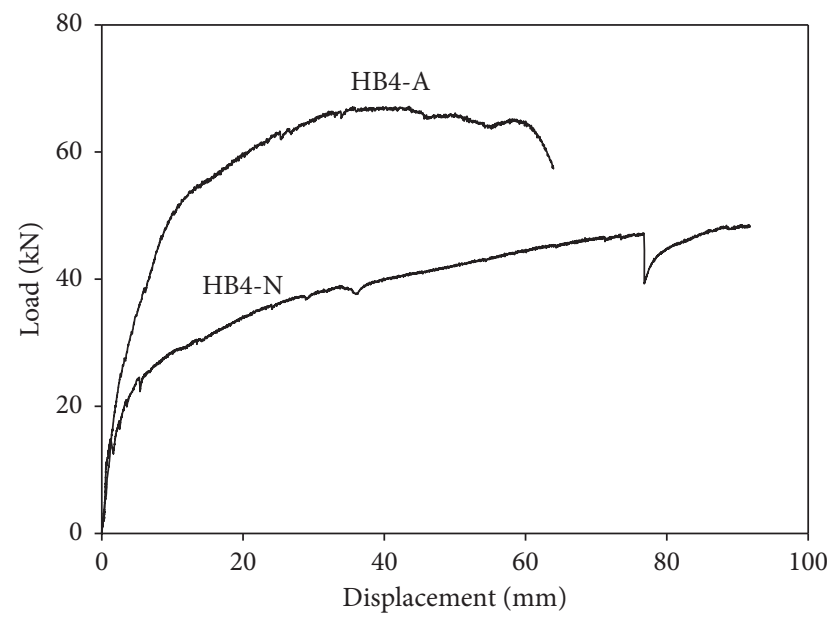

(a)

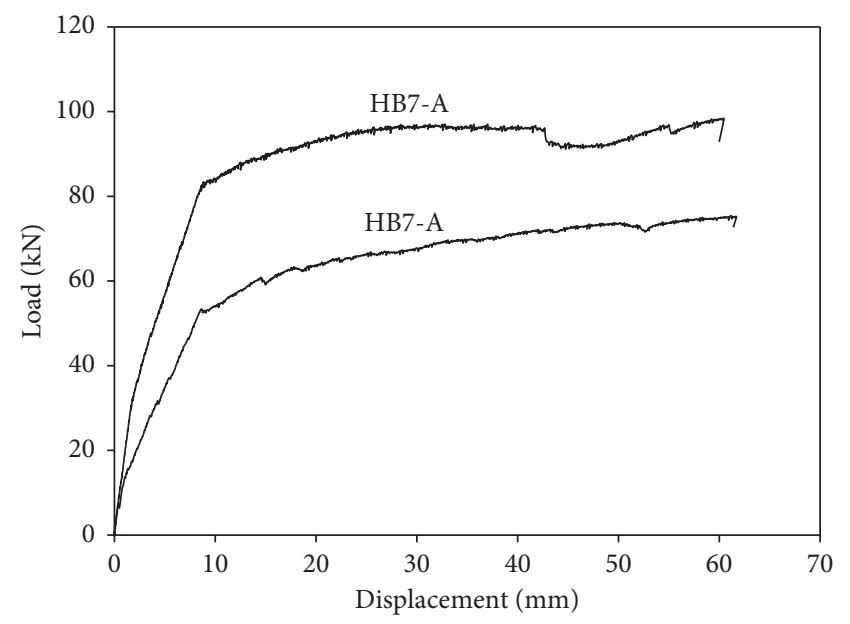

(b)

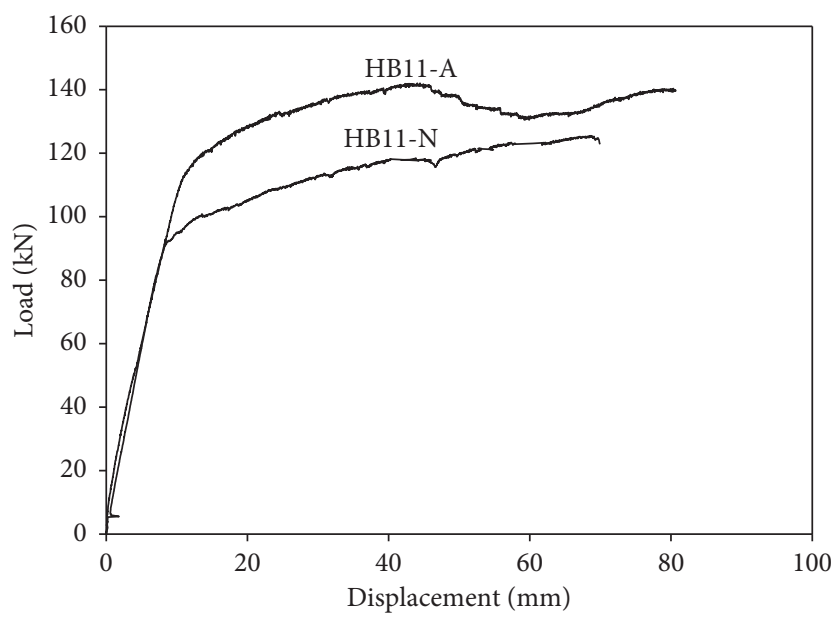

(c)

FIGURE 14: Load-displacement curves of UHPC flexural specimens. 


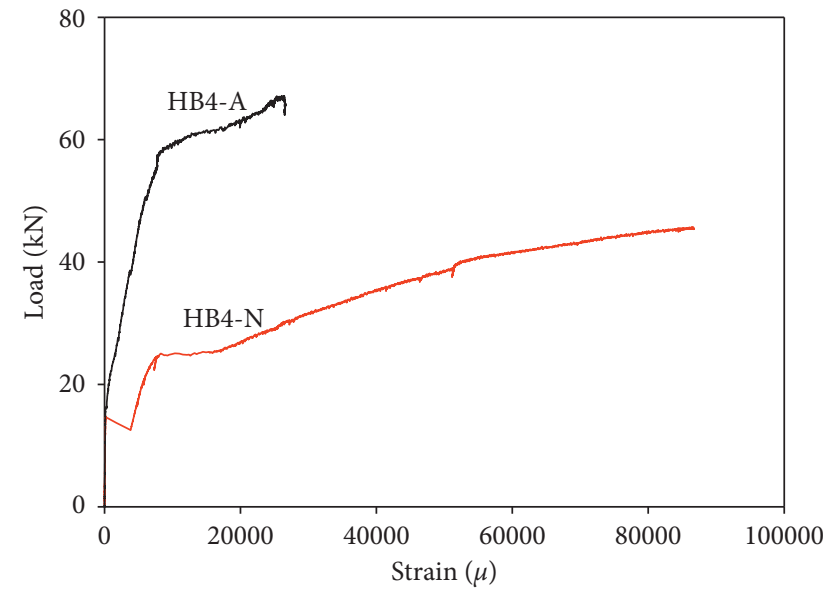

(a)

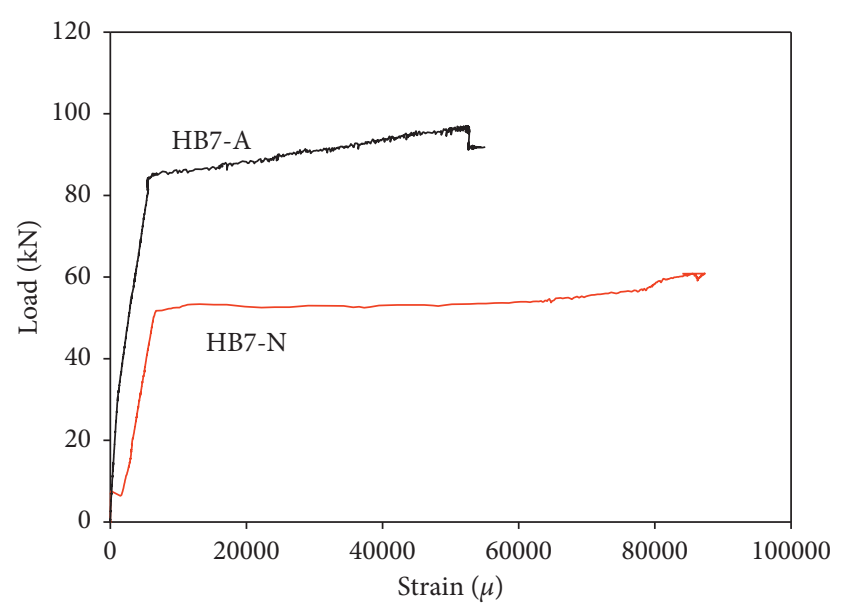

(b)

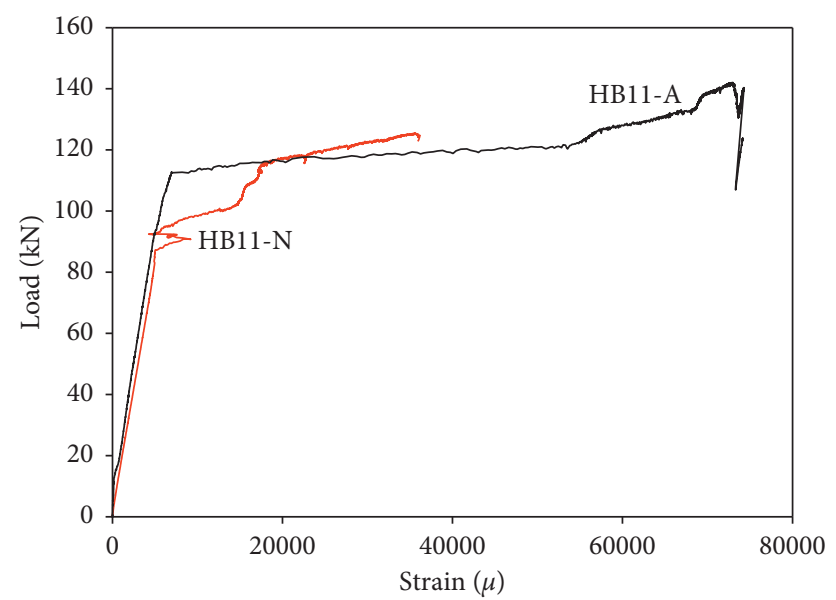

(c)

FIGURE 15: Load-steel strain curves of UHPC flexural specimens.

TABLE 16: Initial crack load and ultimate load and ductility of UHPC flexural specimens.

\begin{tabular}{lcccccc}
\hline & \multirow{2}{*}{ Initial crack load, $P_{\mathrm{cr}}(\mathrm{kN})$} & \multicolumn{2}{c}{ Yield point } & \multicolumn{2}{c}{ Ultimate } & \multicolumn{2}{c}{ Ductility index, $\Delta_{\mathrm{u}} / \Delta_{\mathrm{y}}$} \\
& & $P_{\mathrm{y}}(\mathrm{kN})$ & $\Delta_{\mathrm{y}}(\mathrm{mm})$ & $P_{\mathrm{u}}(\mathrm{kN})$ & $\Delta_{\mathrm{u}}(\mathrm{mm})$ & 14.74 \\
HB4-N & 12.5 & 25.1 & 6.23 & 48.6 & 91.80 & 6.34 \\
HB4-A & 22.0 & 50.4 & 10.1 & 67.2 & 64.04 & 7.43 \\
HB7-N & 15.0 & 51.8 & 8.31 & 75.4 & 61.72 & 6.00 \\
HB7-A & 26.0 & 84.3 & 10.2 & 98.4 & 60.48 & 8.34 \\
HB11-N & 17.4 & 91.2 & 8.38 & 125.5 & 69.93 & 7.05 \\
HB11-A & 46.5 & 114.3 & 11.44 & 142.0 & 80.66 & \\
\hline
\end{tabular}

specimen was similar to that of the plain specimen. The NB10 specimens exhibited decreased strength in the ductility region. This means that the fall-off of UHPC from the NSC beam decreased the strength of the NSC beam after the steel yield.

The NB-20 specimen exhibited increased strength in the region in which steel did not yield, but its maximum load was exhibited at the yield point; after that, it exhibited a trend of slowly decreasing load. The NB-10 and NB-20 specimens exhibited a similar trend after the steel yield. The surface treatment improving adhesion was required to demonstrate sufficient reinforcement performance. If there was insufficient adhesion, the jacketed reinforcement was not beneficial.

Figure 20 displays the crack patterns of NSC flexural specimens. The NB-0 indicated the flexural crack and compressive failure finally occurred between loading points. The NB-10 also indicated the flexural crack. The delamination of reinforcement section started after the yielding point, and the compressive failure occurred at the NSC beam. The NB-20 indicated the typical flexural failure mode and was similar to the result of NS-20. 
14

Advances in Civil Engineering

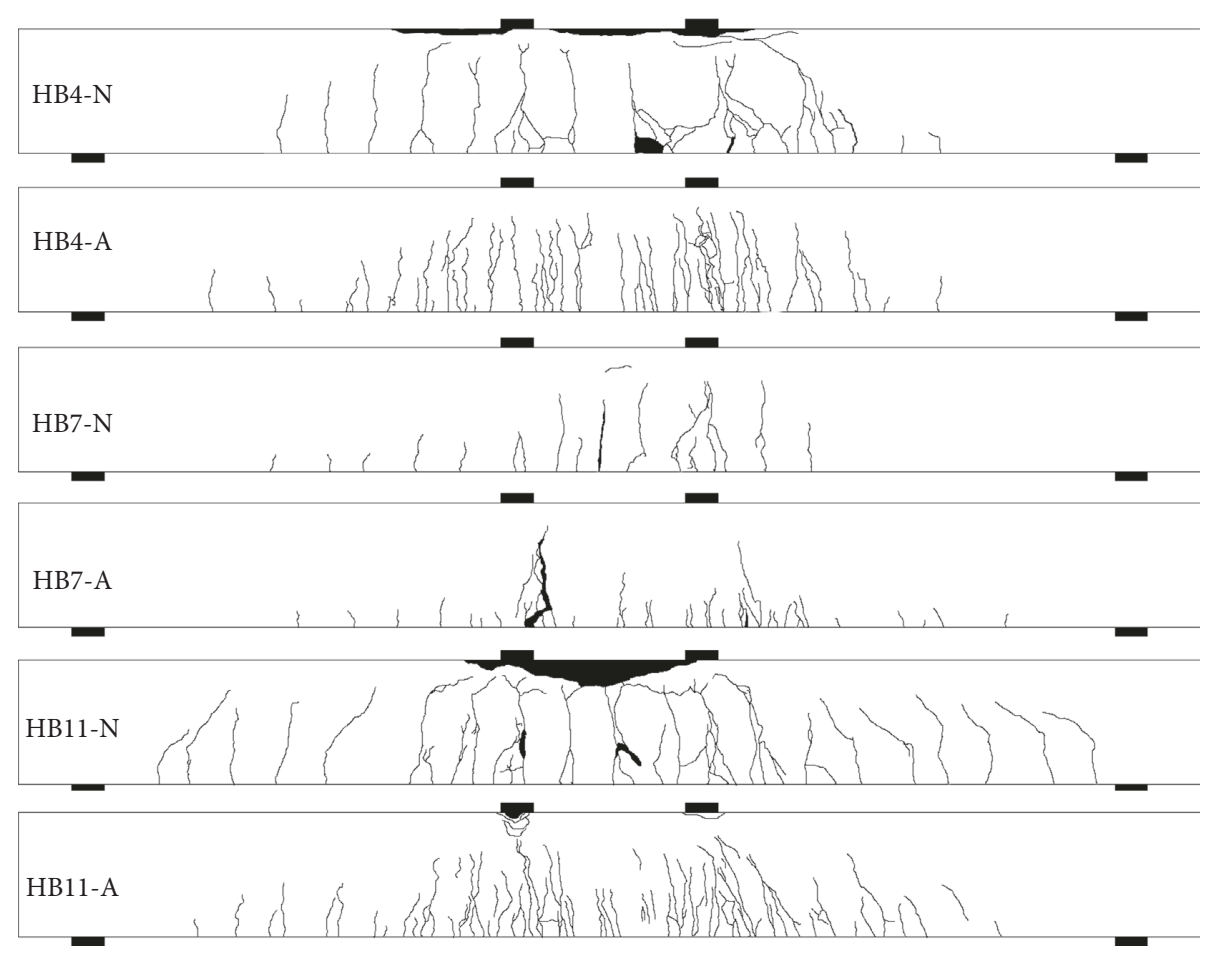

FIGURE 16: Crack patterns of UHPC flexural specimens.

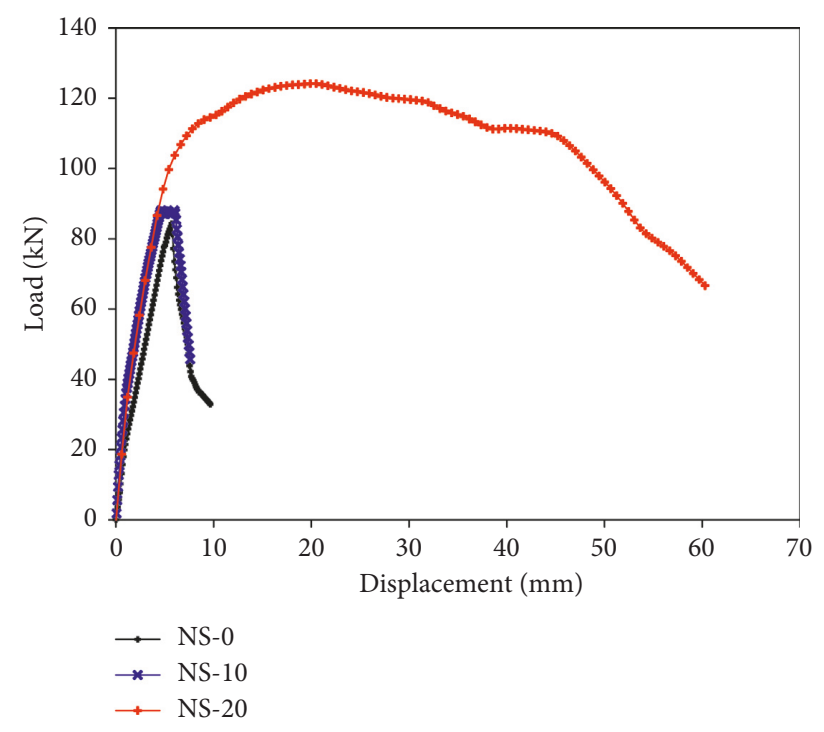

(a)

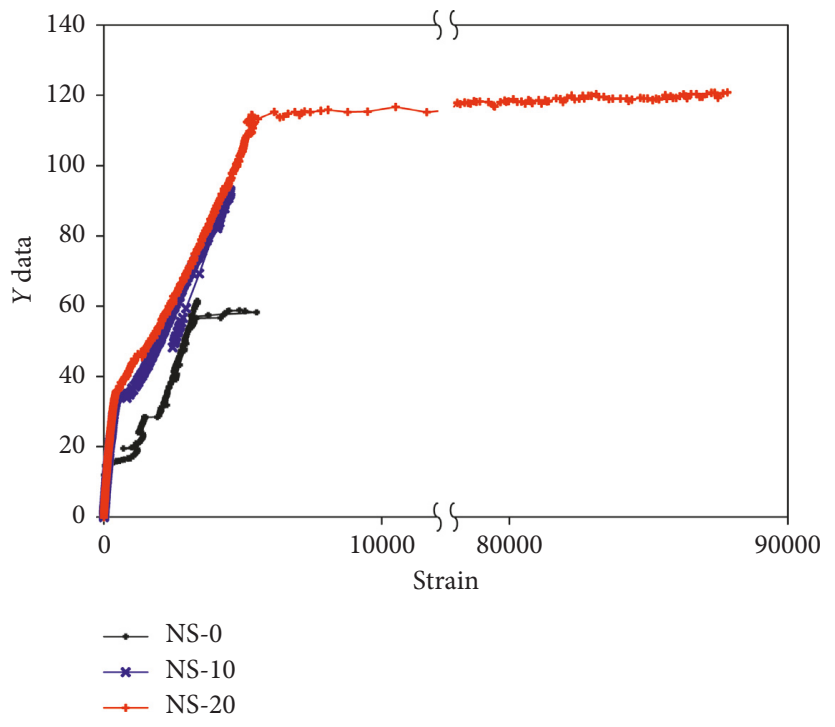

(b)

FIGURE 17: Load-displacement and load-steel strain curve of NSC specimens.

TABLE 17: Shear load of NSC specimens.

\begin{tabular}{lccccc}
\hline & Initial crack load, $V_{\mathrm{i}}(\mathrm{kN})$ & Diagonal tension crack load, $V_{\mathrm{cr}}(\mathrm{kN})$ & Ultimate shear load, $V_{\mathrm{u}}(\mathrm{kN})$ & $V_{\mathrm{i}} / V_{\mathrm{u}}$ & $V_{\mathrm{cr}} / V_{\mathrm{u}}$ \\
\hline NS-0 & 37.0 & 79.4 & 88.1 & 0.42 & 0.65 \\
NS-10 & 12.5 & - & 94.7 & 0.13 & - \\
NS-20 & 44.0 & - & 129.0 & 0.34 & - \\
\hline
\end{tabular}




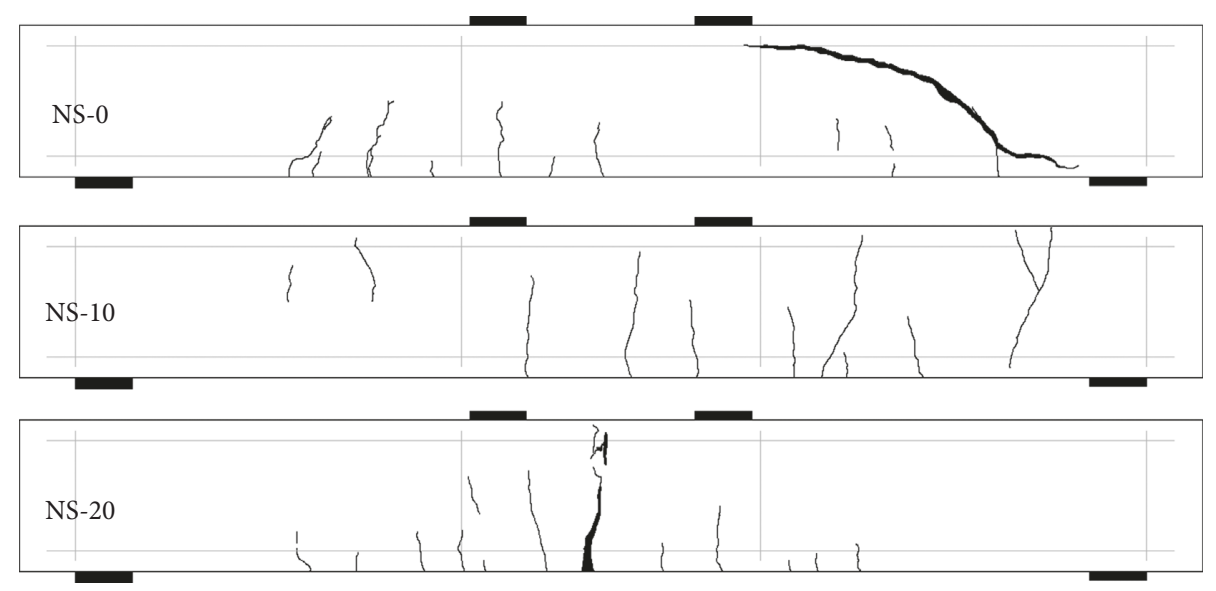

FIgURE 18: Crack patterns of NSC shear specimens.

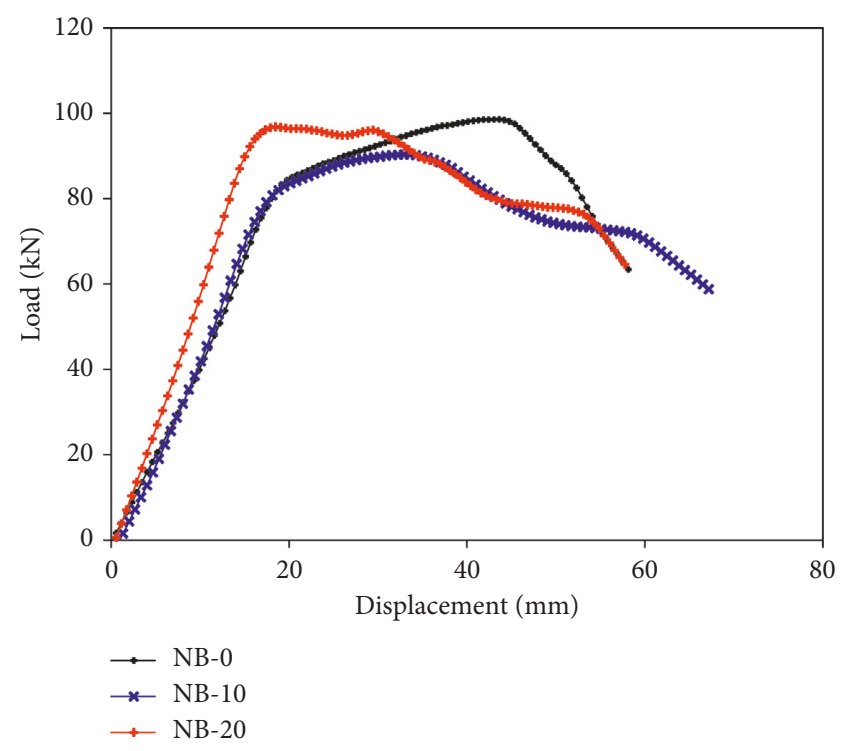

(a)

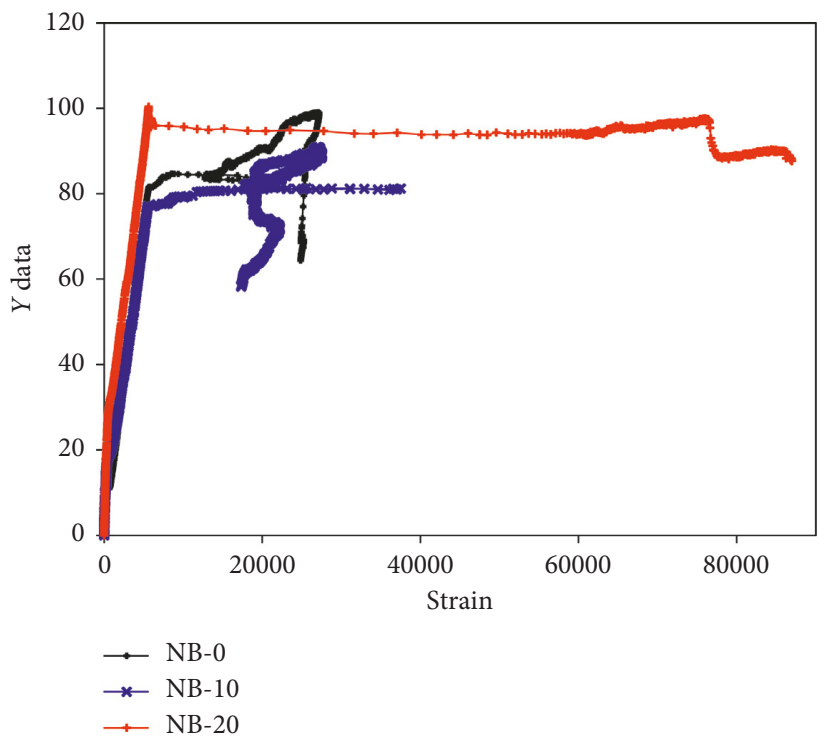

(b)

FIgURE 19: Load-displacement and load-steel strain curve of NB specimens.

TABLE 18: Initial crack load and ultimate load and ductility of NB specimens.

\begin{tabular}{lcccccc}
\hline & \multirow{2}{*}{ Initial crack load, $P_{\mathrm{cr}}(\mathrm{kN})$} & \multicolumn{2}{c}{ Yield point } & \multicolumn{2}{c}{ Ultimate } & \multicolumn{2}{c}{ Ductility index, $\Delta_{\mathrm{u}} / \Delta_{\mathrm{y}}$} \\
& & $P_{\mathrm{y}}(\mathrm{kN})$ & $\Delta_{\mathrm{y}}(\mathrm{mm})$ & $P_{\mathrm{u}}(\mathrm{kN})$ & $\Delta_{\mathrm{u}}(\mathrm{mm})$ & 0.33 \\
NB-0 & 38.0 & 83.8 & 19.20 & 98.6 & 58.16 & 0.25 \\
NB-10 & 29.6 & 77.1 & 16.80 & 90.3 & 67.20 & 57.76 \\
NB-20 & 40.7 & 96.6 & 29.46 & 96.8 & 51 & 0.51 \\
\hline
\end{tabular}

\section{Conclusions}

Material and structural tests were conducted to investigate the performance of $\mathrm{p}-\mathrm{A}$ fiber mixed in concrete. The effect of fiber was evaluated with regard to diameter, length, and twist of fiber. The UHPC beam tests were evaluated to compare the specimens regarding two parameters of p-A fiber: tension reinforcement ratio and shear span-depth ratio. The test results of NSC beams jacketed with UHPC were evaluated by comparison with specimens without UHPC jacketing. From these results, the following conclusions were drawn:

(1) Silica fume was the best material among binders used in this study in terms of compressive strength. The combination specimens with silica fume and zirconium decreased in compressive strength compared with those with only silica fume. However, this combination has the advantage of 


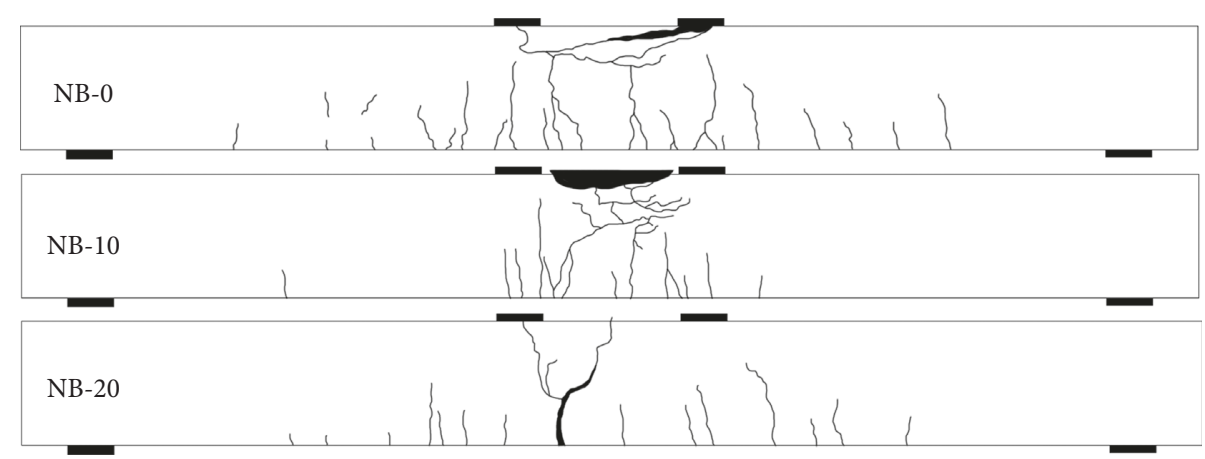

FIgURE 20: Crack patterns of NSC flexural specimens.

improved flowability that reduces costs by decreasing the amount of superplasticizer. The use of only zirconium as a binder greatly reduced the compressive strength compared to only silica fume, so the use of zirconium in a UHPC mix should be used in combination with silica fume. Through further experiments regarding the binder combination, the optimum balance of the flowability and compressive strength should be derived.

(2) From the results of UHPC beam testing with p-A fiber, we identified the improvement of shear and flexural performance. The flexural reinforcement was effective before the yield point, but tension reinforcement steel was dominant after the yield point. The p-A fiber was most effective in reinforcing shear performance in UHPC beams.

(3) From the test results of NSC beams jacketed with UHPC, if the reinforcement thickness was not sufficient, the beam strength decreased after the yield point, and the behavior was similar to that of the plain specimen before the yield point. The results for the NB-20 specimen showed that the reinforcement section is dropped, and the strength gradually decreased after the yield point.

(4) We identified the possibility of p-A fiber for concrete reinforcement. The reinforcement effect of p-A fiber was exhibited in the results of the materials and structure testing. However, these results are inferior to those of previous studies using highstrength steel fiber. Currently, concrete reinforcement through $\mathrm{p}-\mathrm{A}$ fiber is not efficient enough to replace existing fibers. If the reinforcing effect of p-A fiber is improved through various experiments, it may be considered a viable concrete reinforcing fiber.

\section{Data Availability}

The data used to support the findings of this study are available from the corresponding author upon request.

\section{Conflicts of Interest}

The authors declare that they have no conflicts of interest.

\section{Acknowledgments}

This work was supported by National Research Foundation of Korea (No. NRF-2017R1D1A3B03029863) and partially by the Global Excellent Technology Innovation (grant number 10062951) funded by the Ministry of Trade, Industry and Energy (MOTIE) of Korea.

\section{References}

[1] W. Y. Lim and S. G. Hong, "Shear strengthening of RC beam with ultra-high performance concrete beams," Magazine of the Korea Institute for Structural Maintenance and Inspection, vol. 19, no. 4, pp. 29-33, 2015.

[2] B. A. Tayeh, B. H. Abu Bakar, M. A. Megat Johari, and Y. L. Voo, "Mechanical and permeability properties of the interface between normal concrete substrate and ultra high performance fiber concrete overlay," Construction and Building Materials, vol. 36, pp. 538-548, 2012.

[3] N. Baša, M. Ulićević, and R. Zejak, "Experimental research of continuous concrete beams with GFRP reinforcement," Advances in Civil Engineering, vol. 2018, Article ID 6532723, 16 pages, 2018.

[4] P. Zhang, S. Han, S. Ng, and X.-H. Wang, "Fiber-reinforced concrete with application in civil engineering," Advances in Civil Engineering, vol. 2018, Article ID 1698905, 4 pages, 2018.

[5] D. J. Kim, S. H. Park, G. S. Ryu, and K. T. Koh, "Comparative flexural behavior of hybrid ultra high performance fiber reinforced concrete with different macro fibers," Construction and Building Materials, vol. 25, no. 11, pp. 4144-4155, 2011.

[6] M. Pourbaba, E. Asefi, H. Sadaghian, and A. Mirmiran, "Effect of age on the compressive strength of ultra-high-performance fiber-reinforced concrete," Construction and Building Materials, vol. 175, pp. 402-410, 2018.

[7] S. H. Park, D. J. Kim, G. S. Ryu, and K. T. Koh, "Tensile behavior of ultra high performance hybrid fiber reinforced concrete," Cement and Concrete Composites, vol. 34, no. 2, pp. 172-184, 2012.

[8] B. Graybeal and M. Davis, "Cylinder or cube: strength testing of 80 to $200 \mathrm{MPa}$ (11.6 to $29 \mathrm{ksi}$ ) ultra-high-performance fiberreinforced concrete," ACI Materials Journal, vol. 105, no. 6, pp. 603-609, 2008.

[9] D.-Y. Yoo, H.-O. Shin, J.-M. Yang, and Y.-S. Yoon, "Material and bond properties of ultra high performance fiber reinforced concrete with micro steel fibers," Composites Part B: Engineering, vol. 58, pp. 122-133, 2014.

[10] S.-T. Kang and J.-K. Kim, "The relation between fiber orientation and tensile behavior in an ultra high performance 
fiber reinforced cementitious composites (UHPFRCC)," Cement and Concrete Research, vol. 41, no. 10, pp. 1001-1014, 2011.

[11] J. Y. Noh and C. Y. Sung, "Engineering properties of carbon fiber and glass fiber reinforced recycled polymer concrete," Journal of the Korean Society of Agricultural Engineers, vol. 58, no. 3, pp. 21-27, 2016.

[12] R. Contamine, A. Junes, and A. Si Larbi, "Tensile and in-plane shear behaviour of textile reinforced concrete: analysis of a new multiscale reinforcement," Construction and Building Materials, vol. 51, pp. 405-413, 2014.

[13] P. Smarzewski, "Flexural toughness of high-performance concrete with basalt and polypropylene short fibres," Advances in Civil Engineering, vol. 2018, Article ID 5024353, 8 pages, 2018.

[14] Y. Uchida, T. Takeyama, and T. Dei, "Ultra high strength fiber reinforced concrete using aramid fiber," in Proceedings of the FraMCoS-7, pp. 1492-1498, Jeju, South Korea, May 2010.

[15] W. Wang, C. Wu, Z. Liu, and H. Si, "Compressive behavior of ultra-high performance fiber-reinforced concrete (UHPFRC) confined with FRP," Composite Structures, vol. 204, pp. 419-437, 2018.

[16] R. Yu, P. Spiesz, and H. J. H. Brouwers, "Effect of nano-silica on the hydration and microstructure development of ultrahigh performance concrete (UHPC) with a low binder amount," Construction and Building Materials, vol. 65, pp. 140-150, 2014.

[17] E. Ghafari, H. Costa, E. Júlio, A. Portugal, and L. Durães, “The effect of nanosilica addition on flowability, strength and transport properties of ultra high performance concrete," Materials \& Design, vol. 59, pp. 1-9, 2014.

[18] C. K. Park, I. D. Jeong, H. J. Kim, and S. H. Lee, “An experimental study of chloride diffusion coefficient of HVFAC with silica fume types," Proceedings of the Korea Concrete Institute, vol. 21, no. 2, pp. 355-356, 2009.

[19] M.-J. Kim, D.-Y. Yoo, S. Kim, M. Shin, and N. Banthia, "Effects of fiber geometry and cryogenic condition on mechanical properties of ultra-high-performance fiberreinforced concrete," Cement and Concrete Research, vol. 107, pp. 30-40, 2018.

[20] S. Abbas, A. M. Soliman, and M. L. Nehdi, "Exploring mechanical and durability properties of ultra-high performance concrete incorporating various steel fiber lengths and dosages," Construction and Building Materials, vol. 75, pp. 429441, 2015.

[21] H.-H. Lee, "Capacity evaluation of high strength SFRC beams according to shear span to depth ratio," Journal of the Korea Institute for Structural Maintenance and Inspection, vol. 18, no. 3, pp. 76-83, 2014.

[22] I. H. Yang, C. Joh, and B.-S. Kim, "Structural behavior of ultra high performance concrete beams subjected to bending," Engineering Structures, vol. 32, no. 11, pp. 3478-3487, 2010.

[23] D.-Y. Yoo and Y.-S. Yoon, "Structural performance of ultrahigh-performance concrete beams with different steel fibers," Engineering Structures, vol. 102, pp. 409-423, 2015.

[24] Y.-C. Kim, S.-M. Baek, W.-S. Kim, T. H. K. Kang, and Y.-K. Kwak, "An experimental study on flexural behavior of steel fiber reinforced concrete beams using recycled coarse aggregates," Journal of the Architectural Institute of Korea Structure and Construction, vol. 30, no. 3, pp. 39-48, 2014.

[25] G. H. Mahmud, Z. Yang, and A. M. T. Hassan, "Experimental and numerical studies of size effects of ultra high performance steel fibre reinforced concrete (UHPFRC) beams," Construction and Building Materials, vol. 48, pp. 1027-1034, 2013.
[26] Y. L. Voo, W. K. Poon, and S. J. Foster, "Shear strength of steel fiber-reinforced ultrahigh- performance concrete beams without stirrups," Journal of Structural Engineering, vol. 136, no. 11, pp. 1393-1400, 2010.

[27] H. K. Cheong and N. MacAlevey, "Experimental behavior of jacketed reinforced concrete beams," Journal of Structural Engineering, vol. 126, no. 6, pp. 692-699, 2000. 


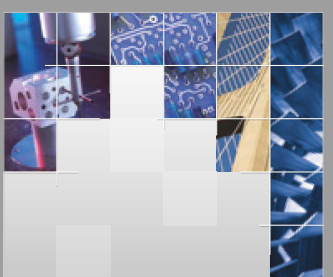

\section{Enfincering}
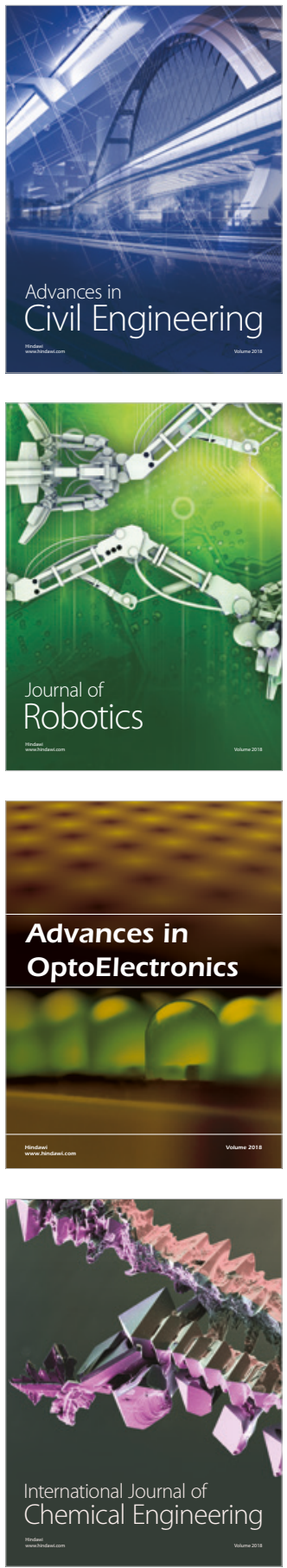

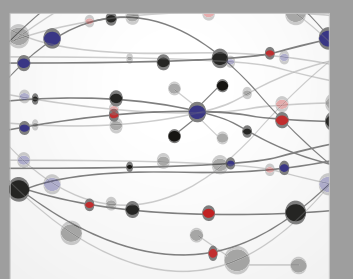

\section{Rotating \\ Machinery}

The Scientific World Journal

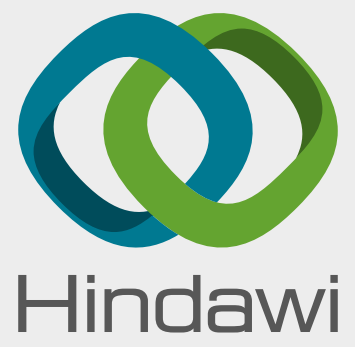

Submit your manuscripts at

www.hindawi.com
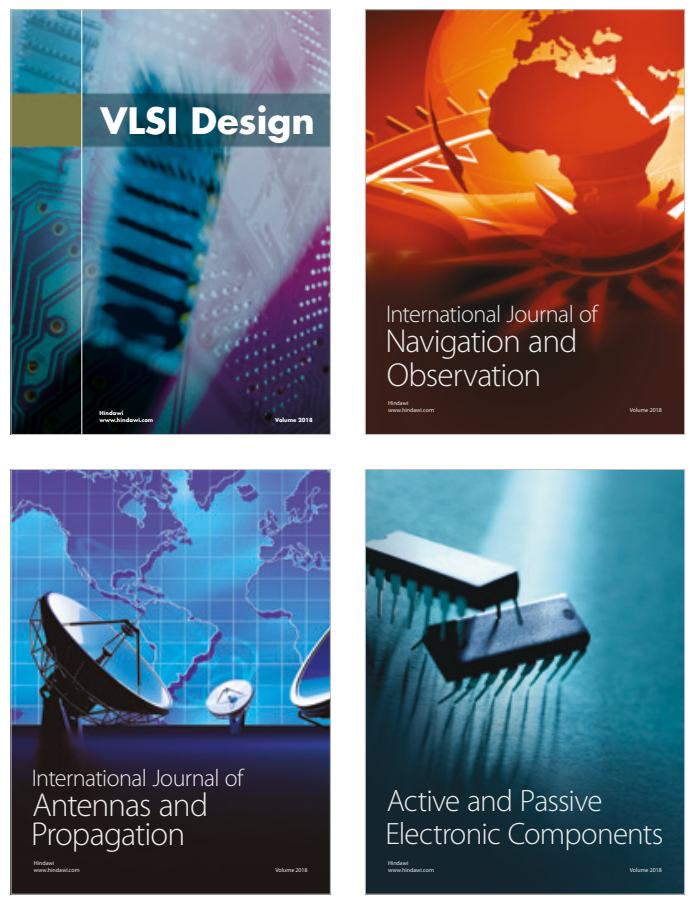
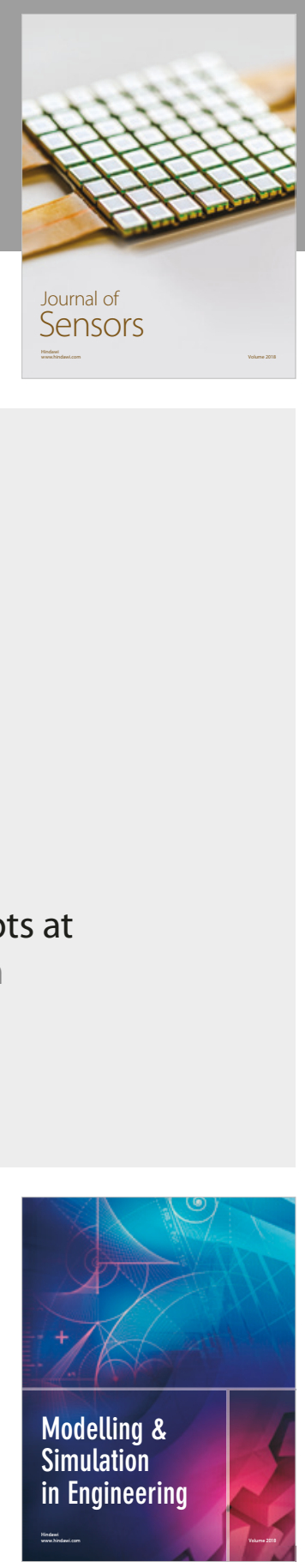

\section{Advances \\ Multimedia}
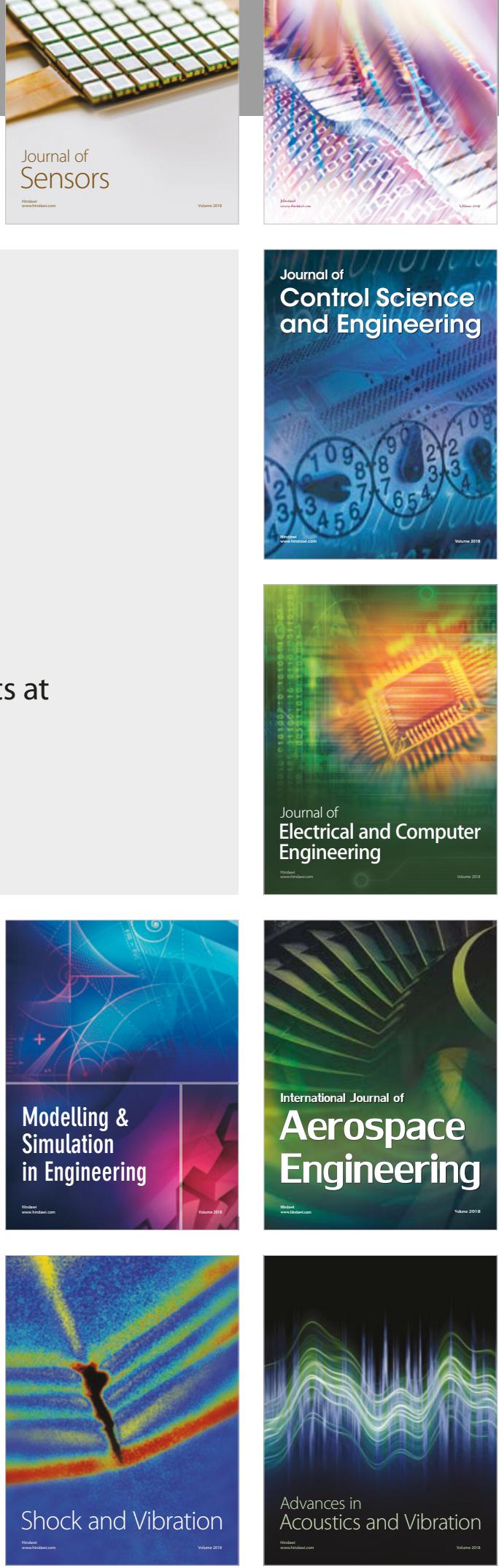